\title{
Vertical Stacked LEGO-PoL CPU Voltage Regulator
}

This paper was downloaded from TechRxiv (https://www.techrxiv.org).

\section{LICENSE}

CC BY 4.0

SUBMISSION DATE / POSTED DATE

$14-09-2021 / 17-09-2021$

CITATION

Chen, Minjie (2021): Vertical Stacked LEGO-PoL CPU Voltage Regulator. TechRxiv. Preprint. https://doi.org/10.36227/techrxiv.16619980.v1

$\mathrm{DOI}$ 


\title{
Vertical Stacked LEGO-PoL CPU Voltage Regulator
}

\author{
Jaeil Baek, Member, IEEE, Youssef Elasser, Student Member, IEEE, Kaladhar Radhakrishnan, Member, IEEE, \\ Houle Gan, Member, IEEE, Jonathan Douglas, Harish K. Krishnamurthy, Member, IEEE, \\ Xin Li, Member, IEEE, Shuai Jiang, Member, IEEE, \\ Charles R. Sullivan, Fellow, IEEE, and Minjie Chen, Senior Member, IEEE
}

\begin{abstract}
This paper presents a $48 \mathrm{~V}-1 \mathrm{~V}$ merged-two-stage hybrid-switched-capacitor converter with a Linear Extendable Group Operated Point-of-Load (LEGO-PoL) architecture for ultra-high-current microprocessors, featuring 3-D stacked packaging and coupled inductors for miniaturized size and vertical power delivery. The architecture is highly modular and scalable. The switched-capacitor circuits are connected in series on the input side to split the high input voltage into multiple stacked voltage domains. The multiphase buck circuits are connected in parallel to distribute the high output current into multiple parallel current paths. It leverages the advantages of switchedcapacitor circuits and multiphase buck circuits to achieve soft charging, current sharing, and voltage balancing. The inductors of the multiphase buck converters are used as current sources to soft-charge and soft-switch the switched-capacitor circuits, and the switched-capacitor circuits are utilized to ensure current sharing among the multiphase buck circuits. A 780 A vertical stacked CPU voltage regulator with a peak efficiency of $91.1 \%$ and a full load efficiency of 79.2\% at an output voltage of $1 \mathrm{~V}$ with liquid cooling is built and tested. This is the first demonstration of a $48 \mathrm{~V}-1 \mathrm{~V}$ CPU voltage regulator to achieve over $1 \mathrm{~A} / \mathrm{mm}^{2}$ current density and the first to achieve $1,000 \mathrm{~W} / \mathrm{in}^{3}$ power density. It regulates output voltage between $0.8 \mathrm{~V}$ and $1.5 \mathrm{~V}$ through the entire 780 A current range.
\end{abstract}

Index Terms-Dc-dc power conversion, hybrid switchedcapacitor circuit, voltage regulator, series-input-parallel-output architecture, vertical power delivery, coupled inductor

\section{INTRODUCTION}

A $S$ the data center industry continues to trend towards consuming more power, efficient power delivery architecture is increasing in significance. Future high performance computing systems (CPUs, GPUs, and TPUs) comprise billions of transistors switching at very fast speeds, and consume hundreds of amperes of current at very low voltage (e.g.

J. Baek, Y. Elasser, M. Chen are with the Department of Electrical and Computer Engineering and the Andlinger Center for Energy and the Environment at Princeton University, Princeton, NJ, 08540, USA.

K. Radhakrishnan, J. Douglas are with Intel, Chandler, AZ, 85226, USA.

H. K. Krishnamurthy is with Intel, Hillsboro, OR, 97124, USA.

H. Gan, X. Li are with Google, Mountain View, CA, 94043, USA.

S. Jiang is with Apple, Cupertino, CA, 95014, USA.

C. R. Sullivan is with Dartmouth College, Hanover, NH, 03755, USA.

This paper is a combination and extension of four previously published conference papers, "LEGO-PoL: A 93.1\% 54V-1.5V 300A Merged-Two-Stage Hybrid Converter with a Linear Extendable Group Operated Point-of-Load (LEGO-PoL) Architecture" in IEEE COMPEL 2019 [1], "LEGO-PoL: A 48V-1.5V 300A Merged-Two-Stage Hybrid Converter for Ultra-High-Current Microprocessor" in IEEE APEC 2020 [2], "A Merged-Two-Stage LEGO-PoL Converter with Coupled Inductors for Vertical Power Delivery" in IEEE ECCE 2020 [3], and "3D LEGO-PoL: A 93.3\% Efficient 48V-1.5V 450A MergedTwo-Stage Hybrid Switched-Capacitor Converter with 3D Vertical Coupled Inductors" in IEEE APEC 2021 [4].

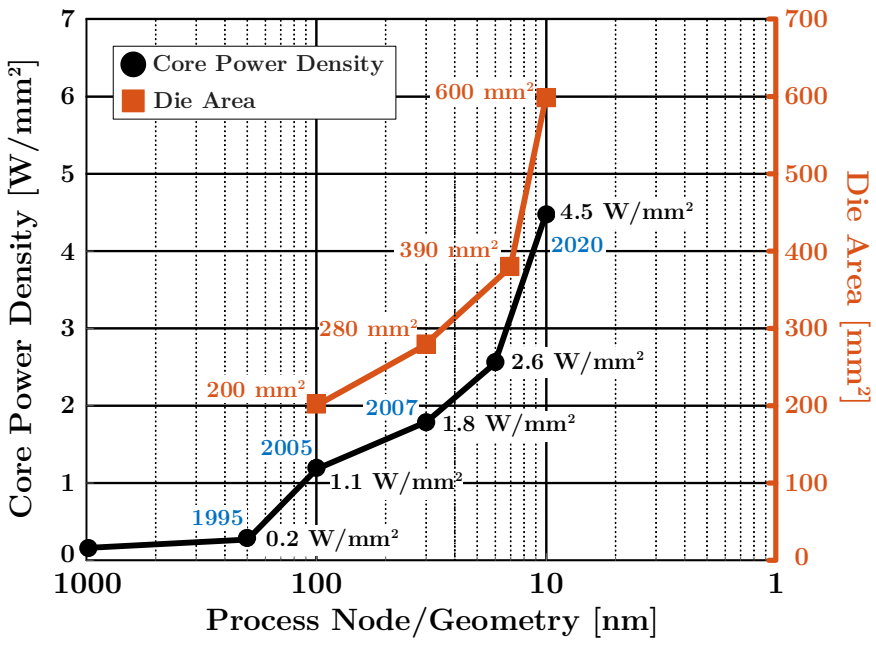

Fig. 1. The breakdown of Dennard scaling [5], [6]. Microprocessors consume higher power per square millimeter in an increasingly larger die area [7], [8], requiring very efficient and miniaturized power delivery from high voltage.

$\geq 250 \mathrm{~A}, \leq 1.5 \mathrm{~V})$ in a small footprint area [9], [10]. Highefficiency, high-power-density, high-bandwidth power electronics are needed to support high performance computing systems. Figure 1 shows the rapid growth of power consumption $(=$ power area density $\times$ die area) of microprocessors against the development of the process nodes. The power area density of microprocessors has exceeded $4.5 \mathrm{~W} / \mathrm{mm}^{2}$, resulting in stringent requirements to improve the power density, and in particular, the current area density, of power electronics. Making the footprint area of voltage regulators smaller than the microprocessor can enable many system level opportunities.

Another emerging trend for efficient power delivery in data centers is powering servers from a high voltage (e.g. $48 \mathrm{~V}$ ). Delivering power at $48 \mathrm{~V}$ reduces power distribution loss and improves UPS deployment flexibility [11]. Various topologies for $48 \mathrm{~V}$-PoL applications have been proposed, including single-stage architectures [12]-[16] and two-stage architectures [17]-[24]. Single-stage architectures are attractive for their low component count, but they often have difficulty achieving high control bandwidth and high output current capability. Two-stage architectures are more suitable for high output current and high control bandwidth applications. They typically consist of an unregulated stage and a regulation stage. The unregulated stage converts a high input voltage (e.g. $48 \mathrm{~V}$ ) to a lower bus voltage (e.g., $\leq 12 \mathrm{~V}$ ) with high efficiency. The regulation stage regulates the output voltage with a high 
control bandwidth. The unregulated stage can be a transformer based topology [17]-[19] or a switched-capacitor based topology [20]-[24]. Transformer based topologies can achieve high heavy-load efficiency but may have inferior light-load efficiency and power density due to transformers. Switchedcapacitor based topologies are becoming increasingly popular due to their transformerless design. They offer advantages in reduced device voltage stress and current stress, and can provide soft charging and soft switching, but usually require resonant inductors to achieve high performance.

This paper develops a modular and scalable $48 \mathrm{~V}-1 \mathrm{~V}$ CPU voltage regulator solution - the Linear Extendable Group Operated Point-of-Load (LEGO-PoL) architecture - which can achieve extreme current area density and perform vertical power delivery. This architecture decouples the high voltage stress and high current stress with automatically balanced building blocks for modularity and scalability. It has a single magnetic component (the output inductor). The size of the dc decoupling capacitors between two stages is very small. The inductive energy storage per watt of the system is low. The switched-capacitor stage can operate at a low switching frequency (e.g. $\leq 300 \mathrm{kHz}$ ) to achieve high efficiency. The buck stage can operate at a much higher switching frequency (e.g. $\geq 1 \mathrm{MHz}$ ) to achieve a high control bandwidth. The coupled inductors further reduce the output inductor size with improved system performance in transient [25]-[32].

A 3D stacked $48 \mathrm{~V}-1 \mathrm{~V}$ CPU voltage regulator with vertical coupled inductors was fabricated and tested to deliver $780 \mathrm{~A}$ of output current with a $0.8 \mathrm{~V}-1.5 \mathrm{~V}$ regulated output voltage range. Vertically delivering the power enables the prototype to achieve a high current area density. The prototype achieved a peak efficiency of $91.1 \%$ and a full load efficiency of $79.2 \%$, a current area density of $1.017 \mathrm{~A} / \mathrm{mm}^{2}$, and a power density of $1000 \mathrm{~W} / \mathrm{in}^{3}$ at $1 \mathrm{~V}, 780 \mathrm{~A}$, and $1 \mathrm{MHz}$ buck switching frequency. The system is liquid cooled when operating above $450 \mathrm{~A}$. The semiconductor junction temperature is maintained below $95^{\circ} \mathrm{C}$ in all operating conditions.

The remainder of this paper is organized as follows: Section II introduces the principles of the LEGO-PoL architecture and its operation mechanisms, including soft charging, automatic current sharing, and automatic voltage balancing. Section III presents the design considerations of the 3D stacked 48 V-1 V point-of-load converter. The experimental setup and measurement results of the prototype are presented in Section IV. Section V provides discussion and further improvements to achieve better performance. Finally, Section VI concludes this paper. An extended discussion of the automatic current balancing mechanism is provided in the Appendix.

\section{LEGO-POL ARCHITECTURE}

\section{A. Principles of the LEGO-PoL Architecture}

Figure 2 shows the key principles of the merged-two-stage LEGO-PoL architecture with $N$ submodules. One LEGO-PoL submodule comprises two building blocks: a 2:1 switchedcapacitor unit and an $M$-phase buck unit. The 2:1 switchedcapacitor unit operates with fixed complementary 50\% duty cycles $\left(\phi_{1}\right.$ and $\left.\phi_{2}\right)$. It is operated at a low frequency to

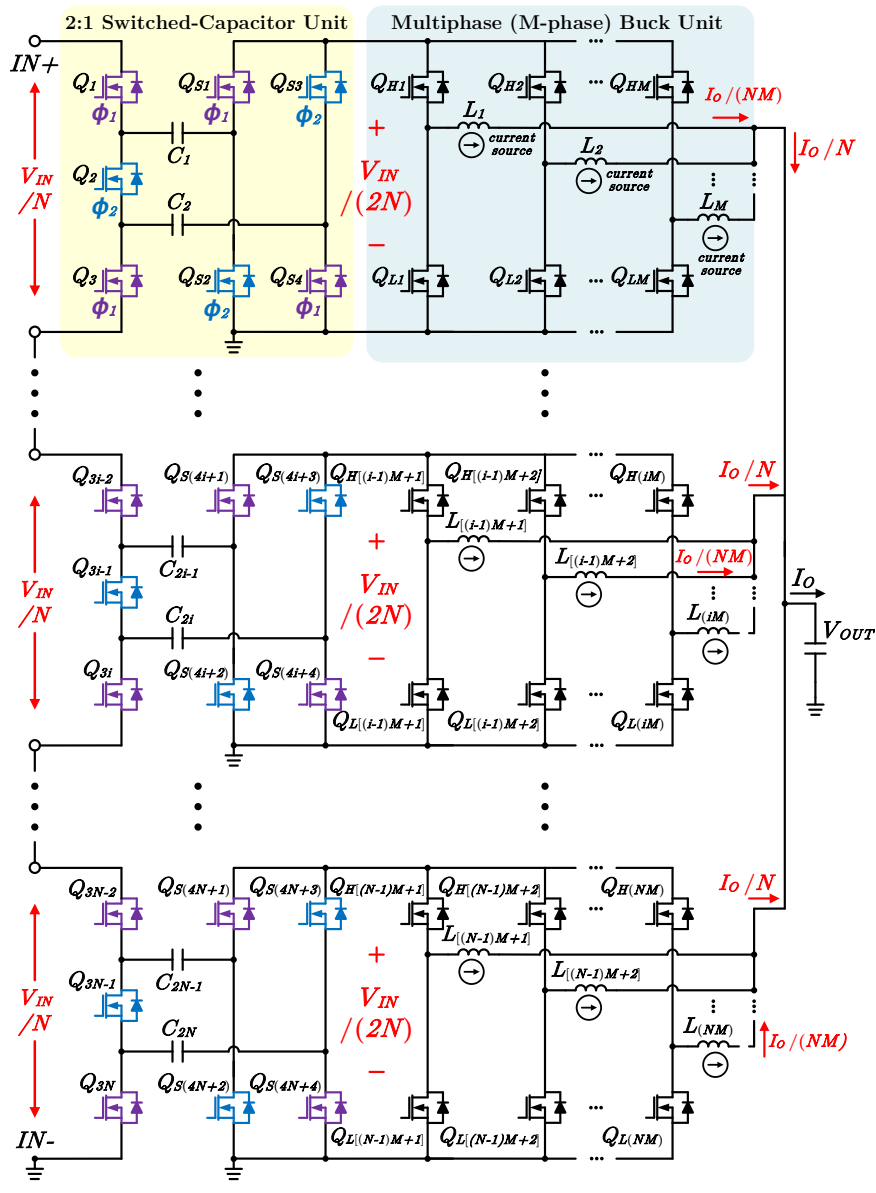

Fig. 2. $N$-submodules of the merged-two-stage LEGO-PoL architecture. One LEGO-PoL submodule comprises one 2:1 switched-capacitor unit and one $M$ phase buck unit. $N$ submodules are connected with input in series and output in parallel. The LEGO-PoL architecture can be linearly extended for different input voltage and output current ranges.

reduce switching losses and achieve high efficiency. The buck unit makes use of interleaving operation at a higher switching frequency for high control bandwidth. There is no resonant inductor in the switched-capacitor unit and no large dc decoupling capacitor between the two stages. The two stages are functionally merged: the buck units act as current sources to soft-charge the switched capacitors.

The LEGO-PoL architecture is highly modular and scalable. The number of submodules can be extended to cover a wider operation range in both the voltage and current domains. With buck units as the output stage, the LEGO-PoL architecture can leverage state-of-the-art voltage-mode or current-mode control techniques that have been developed for voltage regulation modules (VRMs). The $N$ series-connected 2:1 switchedcapacitor units split the input voltage into $N$ voltage domains. The $N$ parallel-connected buck units divide the output current into $N$ current paths, and each individual phase of the buck units only delivers $\frac{1}{M \times N}$ of the output current. The virtual intermediate bus voltage is $\frac{1}{2 N}$ of the input voltage $\left(\frac{V_{I N}}{2 N}\right)$. By equally distributing high input voltage stress and high output current stress into each module, the architecture can utilize lower rated semiconductor devices with uniformly distributed heat dissipation across the submodules. 


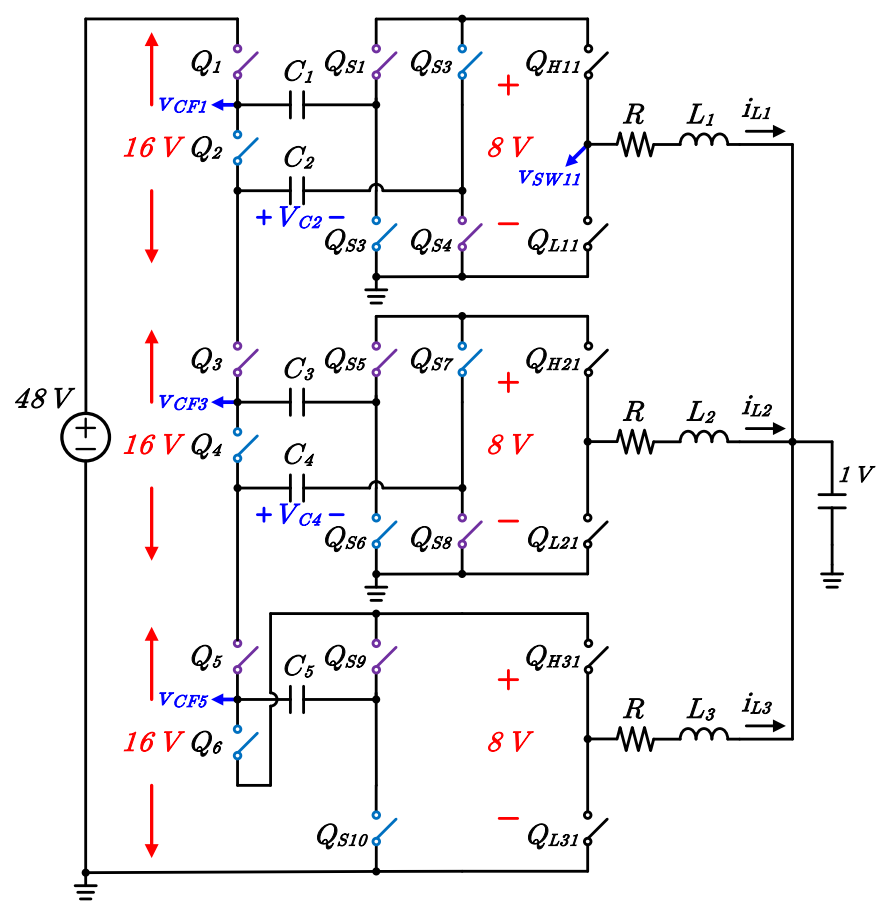

Fig. 3. Topology of a three submodule merged-two-stage LEGO-PoL converter with $48 \mathrm{~V}$ input voltage and $1 \mathrm{~V}$ output voltage for investigating the operation mechanisms. Single phase buck converters are used to simplify the analysis. The switches with purple color are controlled by a PWM signal $\phi_{1}$, while the switches with blue color are controlled by a PWM signal $\phi_{2}$.

\section{B. Operation Mechanisms of the LEGO-PoL Architecture}

The LEGO-PoL architecture decouples the voltage stress, current stress, and dynamic requirements and addresses these design challenges. In this section, we present the soft switching, soft charging, current sharing, and voltage balancing mechanisms in detail. Figures 3 and 4 show a topology and operational waveforms of a LEGO-PoL converter comprising three $(N=3) 2: 1$ switched-capacitor units and three singlephase $(M=1)$ buck units to illustrate the operation mechanisms. The switched-capacitor units in Fig. 3 are simplified from Fig. 2. The series-connected switches in Fig. 2, such as $Q_{3}$ and $Q_{3 i-2}$, can be merged as one switch, $Q_{3}$ in Fig. 3. One switch $\left(Q_{3 N}\right)$, one capacitor $\left(C_{2 N}\right)$, and two synchronous rectifier switches $\left(Q_{S(4 N+3)}\right.$ and $\left.Q_{S(4 N+4)}\right)$ in the third 2:1 switched-capacitor unit can be removed because the voltage across $C_{2 N}$ is zero. Switch $Q_{6}$ is connected to the output of the third 2:1 switched-capacitor unit.

1) Soft Switching and Soft Charging: There are two design options for the LEGO-PoL converter. The first is when the LEGO-PoL converter is designed with a very low parasitic inductance (e.g., $\ll 1 \mathrm{nH}$ ) along the current path between the switched-capacitor stage and the buck stage. In this option, the capacitors of the switched-capacitor stage are used as the input capacitors of the buck stage, and the decoupling capacitor between the two stages is eliminated. Buck inductor currents can only conduct through each switched-capacitor unit when the high-side buck switches $\left(Q_{H x}\right)$ are turned on. Zerocurrent-switching (ZCS) is achieved in the switched-capacitor units by coordinating the switching sequences of the switched-

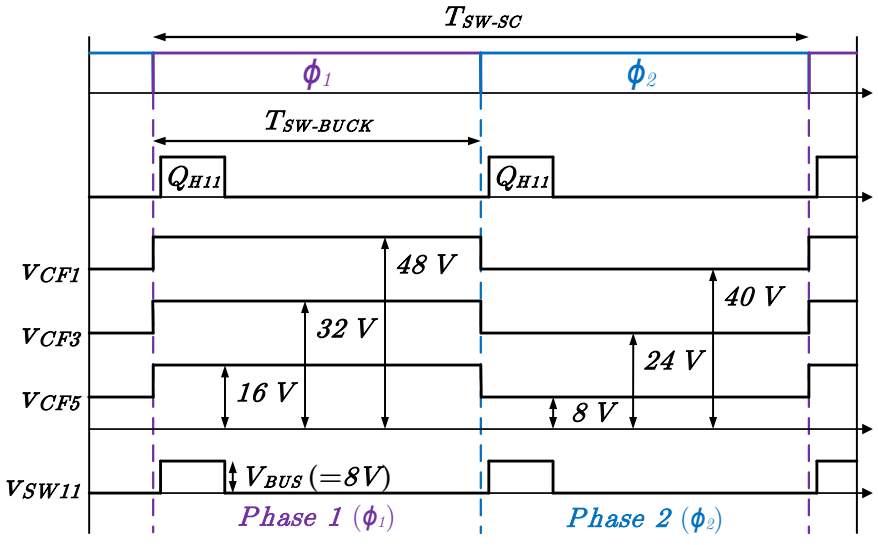

Fig. 4. Operational waveforms of the LEGO-PoL converter shown in Fig. 3.

capacitor units and buck units. The key principle is to change the state of the switched-capacitor units during the freewheeling state of the buck units (Fig. 4). This is of particular importance when selecting the switching frequencies of the switched-capacitor stage and buck stage. In contrast to the resonant hybrid-switched-capacitor converter, which achieves soft charging operation by placing an inductor between two capacitors, the LEGO-PoL architecture achieves it by utilizing the inductors in the buck stage. The capacitors of the switchedcapacitor units are always charged and discharged by the buck stage which acts as a current source.

The second possible design option is when the LEGO-PoL converter does not have a low enough parasitic inductance (e.g., $>1 \mathrm{nH}$ ). In this option, a capacitor between two stages is used. This capacitor is large enough to filter the high frequency pulsating current from the buck stage, and is small enough to maintain low charge sharing loss. The current flowing in the switched-capacitor units is the input current of the buck units, filtered by the parasitic inductance and filter capacitance. The switching frequencies of the switched-capacitor units and buck units can be independently selected. This design option is implemented in the developed prototype, using the switching control demonstrated in Fig. 4. The design of this filter capacitor is discussed in Section III-B.

2) Automatic Current Sharing and Voltage Balancing: The automatic current sharing and voltage balancing mechanism of the LEGO-PoL architecture can be explained by analyzing the current flow in the two switching phases in Fig. 3. In each switching cycle, capacitors $C_{2}$ and $C_{4}$ are charged by one current source in $\phi_{1}$, and discharged by another current source in $\phi_{2}$. Due to the charge balancing requirements of the switched capacitors, the two current sources have to be equal, leading to current sharing between two adjacent modules, and sequentially current sharing to all modules. For example, $C_{2}$ is discharged by $i_{L_{2}}$ in $\phi_{1}$, and charged by $i_{L_{1}}$ in $\phi_{2} . C_{3}$ is charged by $i_{L_{2}}$ in $\phi_{1}$, and discharged by $i_{L_{2}}$ in $\phi_{2}$. As described in Appendix I, the charge balance requirement of $C_{2}$ and $C_{3}$ in one switching period forces $i_{L_{1}}$ to be equal to $i_{L_{2}}$ in steady state operation. Benefiting from a similar switched-capacitor mechanism, the automatic current sharing leads to automatic voltage balancing between 


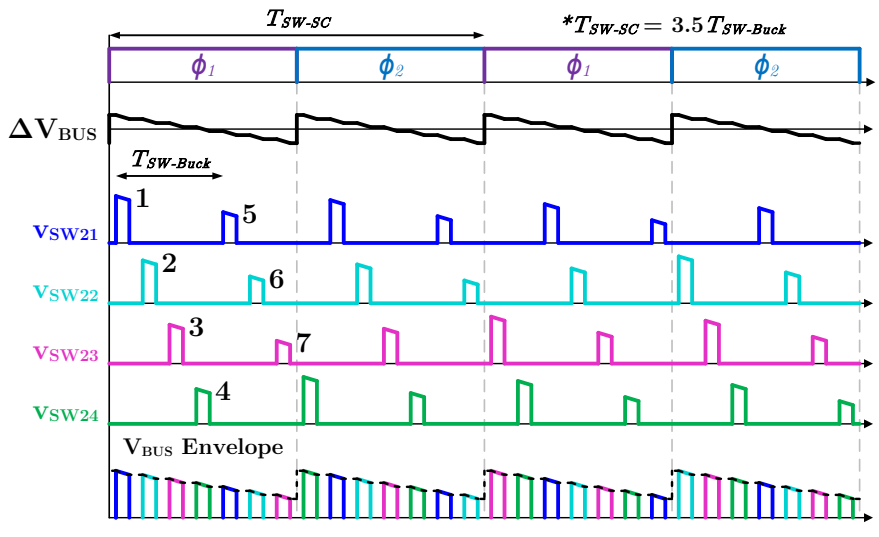

Fig. 5. An example of passive phase current balancing of the LEGO-PoL converter. Phase rotation enables each buck switch node to have the same average input voltage.

the series stacked switched capacitors. With these features, the LEGO-PoL architecture can handle a very high output current.

3) Passive Phase Current Balancing: The LEGO-PoL architecture automatically balances the current between each submodule. The phase currents of each module can be balanced by coordinating the selection of the switching frequencies of the switched-capacitor stage and buck stage. Since the LEGO-PoL architecture removes large dc decoupling capacitor between the two stages, the virtual intermediate bus voltages contain a higher ripple, which may cause phase current mismatch in a buck unit. There are a few methods to balance the phase currents in the presence of this ripple, including current mode control. The duty ratios of the buck unit switches can be actively modulated to compensate for the input voltage ripple and balance phase currents. Another way is to use a passive phase rotating scheme to balance the current as depicted in Fig. 5. When the buck switching frequency is chosen as

$$
f_{\text {Buck }}=\frac{2 k+1}{2} f_{\text {SC }}, \quad k=1,2,3, \cdots
$$

where $f_{\text {Buck }}$ and $f_{\mathrm{SC}}$ are the switching frequency of the buck stage and switched-capacitor stage, respectively, an odd number (seven, in the example of Fig. 5) of buck switching occurrences happen during a half switching cycle of the switched-capacitor stage. This results in rotating through the different buck switches, each taking a turn as the one turned on at the highest $V_{B U S}$ ripple, and resulting in identical average input voltage across all buck switch nodes.

\section{Vertical Stacked LEGO-PoL Converter Design}

Vertical power delivery for microprocessors can increase current area density $\left(\mathrm{A} / \mathrm{mm}^{2}\right)$, create space for communication interconnects, reduce $I^{2} R$ losses in the power delivery network, and improve transient response by reducing parasitic impedances [35]-[38]. This section details how to design a vertical stacked LEGO-PoL converter exceeding $1 \mathrm{~A} / \mathrm{mm}^{2}$, approaching the area power density of the silicon core (Fig. 1).

Figure 6 shows the schematic of a 48 V-1 V 780 A LEGOPoL converter with three series-stacked 2:1 switched-capacitor units and three parallel-connected four-phase buck units with

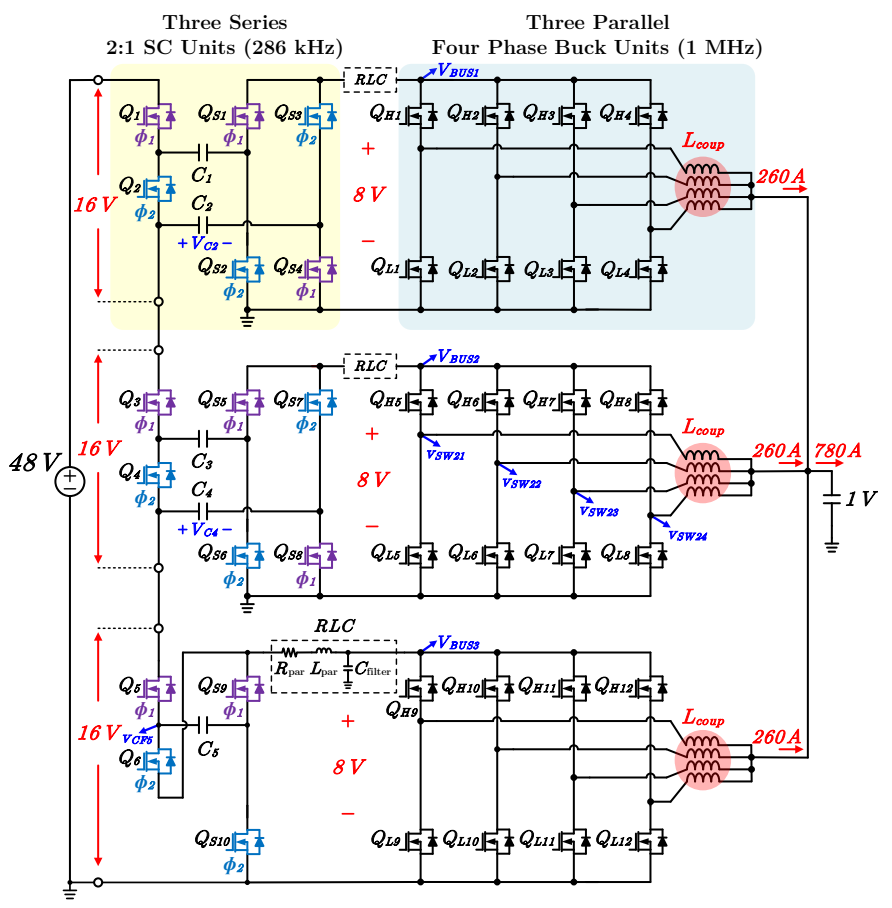

Fig. 6. A $48 \mathrm{~V}$ to $1 \mathrm{~V}, 780$ A LEGO-PoL design with three $(N=3)$ stacked sub-modules. The switched-capacitor units switch at $286 \mathrm{kHz}$, and the fourphase $(M=4)$ buck units switch at $1 \mathrm{MHz}$. Each phase delivers $65 \mathrm{~A}$ of peak current at an effective current ripple frequency of $4 \mathrm{MHz}$ due to interleaving and magnetic coupling. $R_{\mathrm{par}}$ and $L_{\mathrm{par}}$ are the lumped parasitic resistance and inductance of the current paths in the switched-capacitor stage. $C_{\text {filter }}$ is a small high frequency filter capacitor of the buck stage.

coupled inductors. This design steps down $48 \mathrm{~V}$ to $8 \mathrm{~V}$ through the three $2: 1$ switched-capacitor units, and then $8 \mathrm{~V}$ to $1 \mathrm{~V}$ through the four-phase buck units. The $8 \mathrm{~V}$ interconnect is a virtual intermediate bus with a significant voltage ripple. The twelve phases each deliver a peak current of $65 \mathrm{~A}$ with regulated output voltage. To enable vertical power delivery, the inductors are used as a link between the motherboard and the remainder of the converter. Parasitic resistance $\left(R_{\mathrm{par}}\right)$ and inductance $\left(L_{\mathrm{par}}\right)$ are considered to design a high frequency input filter capacitor $\left(C_{\text {filter }}\right)$ for the buck stage. Detailed design considerations of this vertical stack procedure for a high current density of $1 \mathrm{~A} / \mathrm{mm}^{2}$ are provided in the following subsections. Figure 7 and Figure 8 show the PCB layout and mechanical demonstration of the $48 \mathrm{~V}-1 \mathrm{~V} 780$ A vertical stacked LEGO-PoL converter with lateral or vertical power delivery from the motherboard to the CPU.

\section{A. Series-Stacked Switched-Capacitor Stage}

Three series stacked 2:1 switched-capacitor units split $48 \mathrm{~V}$ high input voltage into smaller $16 \mathrm{~V}$ voltage domains to enable the utilization of low-voltage-rating devices with low on-resistance. The voltage stresses on the active switches are either $V_{B U S}$ or $2 V_{B U S}$, as the voltage blocked by the switches is always clamped by the capacitors. Due to low voltage stress and low switching frequency, switches in the switchedcapacitor stage are implemented as standards MOSFETs.

In many resonant switched-capacitor designs, the capacitors need to be carefully selected because the capacitance value 


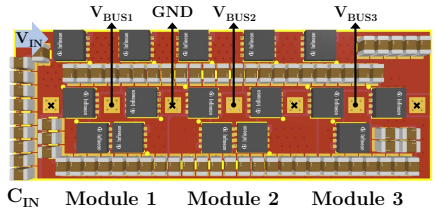

(a)

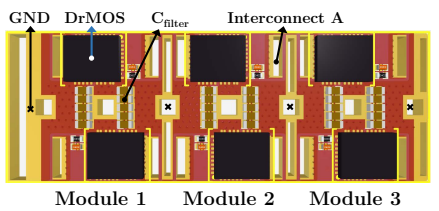

(c)

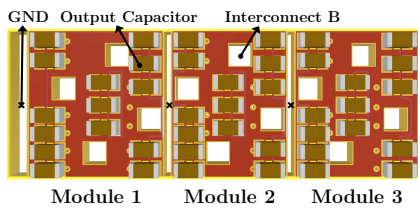

(e)

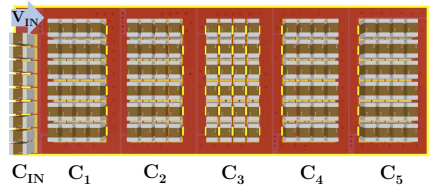

(b)

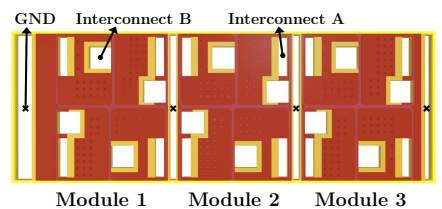

(d)

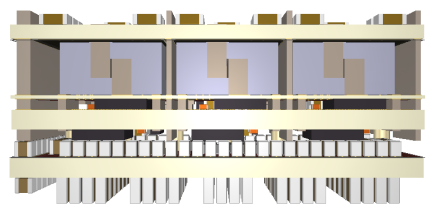

(f)
Fig. 7. PCB layout of the vertical stacked LEGO-PoL converter. PCB layout has a $780 \mathrm{~mm}^{2}$ of area constraint to achieve $1 \mathrm{~A} / \mathrm{mm}^{2}$. (a) Switched-capacitor board, top view (12-layer, $2 \mathrm{oz}, 2.2 \mathrm{~mm}$ ). (b) Switched-capacitor board, bottom view. (c) Buck board (12-layer, $2 \mathrm{oz}, 2.2 \mathrm{~mm}$ ). The top and bottom views are identical. (d) Interposer board (4-layer, $2 \mathrm{oz}, 0.8 \mathrm{~mm}$ ). (e) Output motherboard (4-layer, $3 \mathrm{oz}, 1.6 \mathrm{~mm}$ ). (f) Full system assembly. Power is delivered from the bottom (48 V, 16.25 A side) to the top ( $1 \mathrm{~V}, 780 \mathrm{~A}$ side).

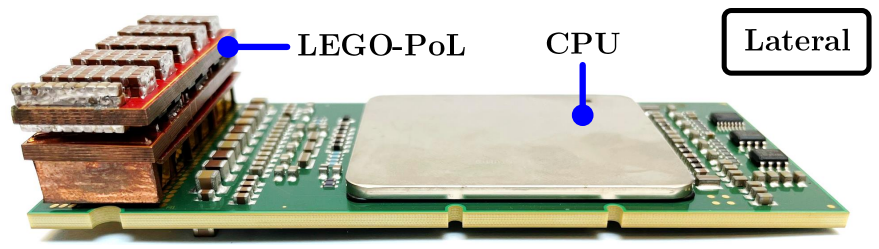

(a)

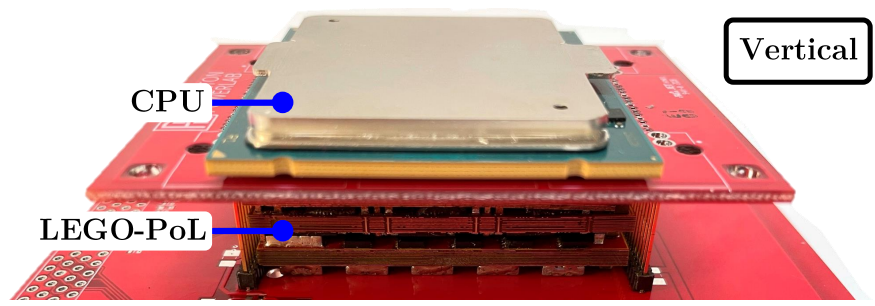

(b)

Fig. 8. Mechanical demonstration of the $48 \mathrm{~V}-1 \mathrm{~V} 780$ A vertical stacked LEGO-PoL converter: (a) Lateral to an Intel Itanium 9150 CPU (TDP $104 \mathrm{~W}$ ) and (b) Vertical to an Intel Xeon E7-2870 CPU (TDP $130 \mathrm{~W}$ ).

determines the soft charging, soft switching, or resonant operation. Capacitance drifting and degradation may have a significant impact on the system performance. The LEGOPoL converter eliminates the resonant operation and achieves soft charging and soft switching operations by using the buck inductors as current sources. The capacitance values do not need to be precisely controlled. The system can tolerate capacitance variations that result from dc bias, temperature variation, and capacitance degradation.

Figures $7 \mathrm{a}$ and $7 \mathrm{~b}$ show the component placement of the switched-capacitor stage within $780 \mathrm{~mm}^{2}$ of the printed circuit

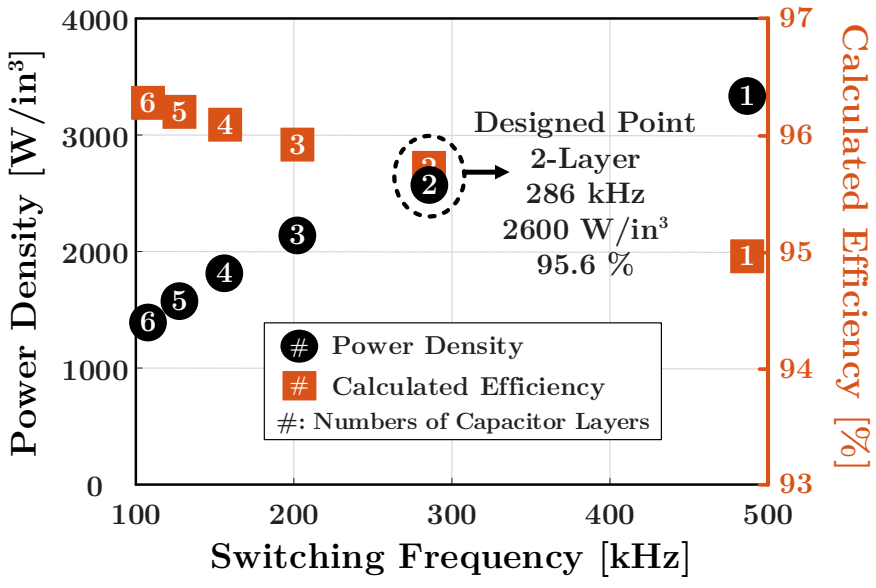

Fig. 9. Power density and calculated efficiency of the switched-capacitor stage according to the layers of bottom capacitors. The efficiency is obtained based on a developed loss model. The switching frequency is chosen to fix the maximum intermediate bus voltage ripple at $3 \mathrm{~V}$ when $V_{\text {out }}=1 \mathrm{~V}$ and $I_{\text {out }}=780 \mathrm{~A}$ in this graph.

board (PCB) area. On the top layer, MOSFETs and capacitors are placed as close as possible to reduce parasitics. Then, the empty space is filled with copper traces and capacitors. On the bottom layer, the capacitors are fully modularized to optimize the current path and reduce the PCB conduction loss. The capacitance of the switched capacitors is selected to optimize the power density, efficiency, and intermediate bus voltage ripple. The bus voltage ripple can be designed considering the voltage rating of the semiconductor devices. Selecting a $3 \mathrm{~V}$ intermediate bus voltage ripple for this application, more layers of capacitors enable lower switching frequency operation and higher efficiency but deteriorates the power density as depicted in Fig. 9. In the prototype, two layers of 0805 capacitors are stacked for a $286 \mathrm{kHz}$ of switching frequency, $2600 \mathrm{~kW}$ power density, and $95.6 \%$ full load efficiency of the switched-capacitor stage. Figure 10 shows the gate drive structure for three series stacked 2:1 switchedcapacitor units. A pair of 50\% complementary gate driver signals $\left(\phi_{1}\right.$ and $\left.\phi_{2}\right)$ is used. This is a simple and scalable charge pump circuit for generating the bias voltage for the floating MOSFETs and can be fully integrated.

\section{B. Virtual Intermediate Bus Parasitics}

Due to the high frequency operation of the buck stage, a small parasitic inductance between two stages can cause current ringing and increase the stress in the switched-capacitor stage. Figure 11 shows an equivalent RLC circuit of one submodule of the LEGO-PoL converter. The switched-capacitor stage is modeled as a sawtooth voltage source whose frequency is twice of that of the switched-capacitor stage $\left(2 f_{\mathrm{SC}}\right)$. The buck unit is modeled as a pulse wave current source with 4 times the switching frequency of the buck stage $\left(4 f_{\text {Buck }}\right) . L_{\mathrm{par}}$ and $R_{\mathrm{par}}$ are the lumped parasitic inductance and resistance along the current paths in the switched-capacitor stage. $C_{\text {filter }}$ is a small input capacitor of the buck stage to smooth the high frequency current. The input current of four-phase buck units $\left(i_{\text {Buck }}\right)$ is clamped by the inductor current, while the current 


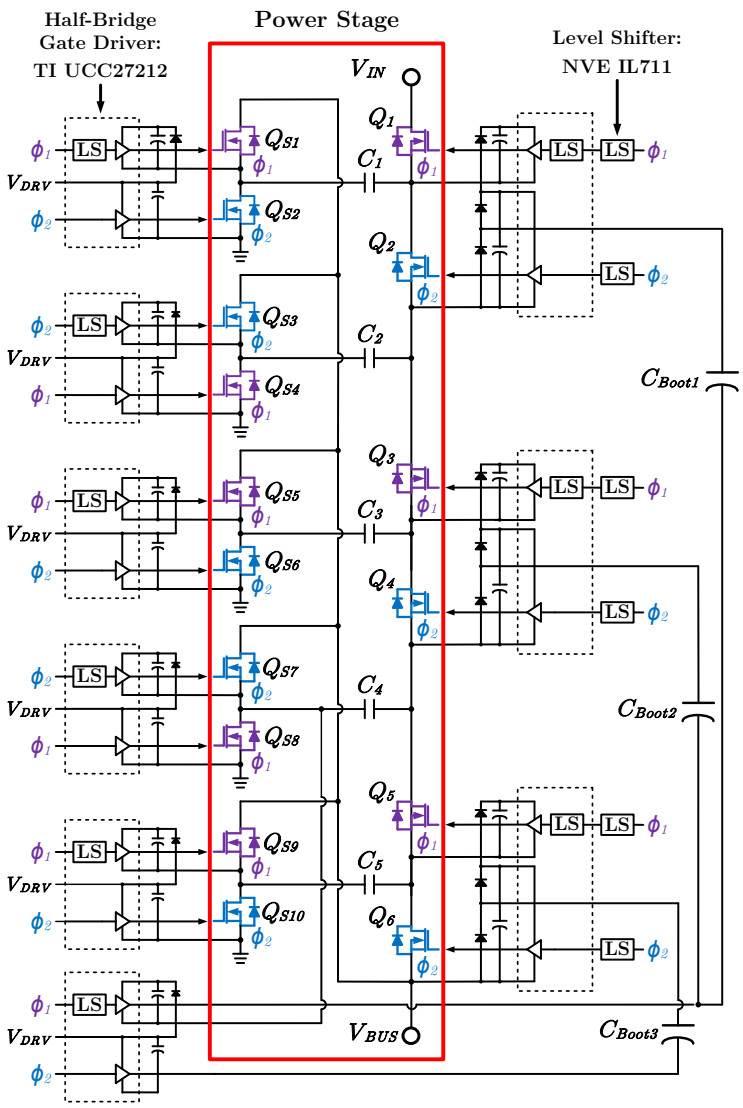

Fig. 10. A modular gate drive circuit for the switched-capacitor stage, which is placed on the switched-capacitor board, outside the power stage.

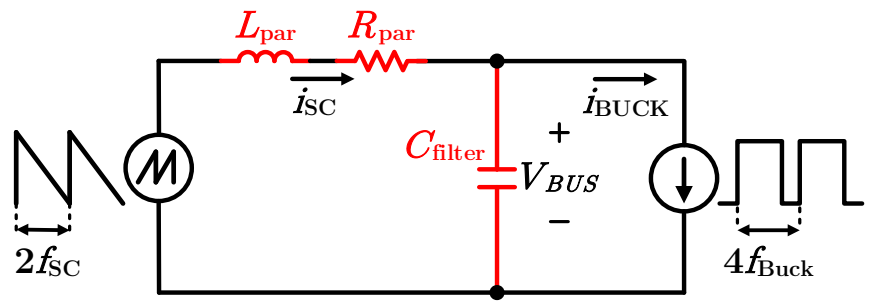

Fig. 11. Equivalent circuit of one submodule of the merged-two-stage LEGOPoL converter. The 2:1 switched-capacitor unit is represented as a sawtooth voltage source with a frequency of $2 \times f_{\mathrm{SC}}$ and an amplitude of ripple voltage of the switched-capacitor. The four-phase buck unit can be represented as a pulse wave current source with a frequency of $4 \times f_{\text {Buck. }}$.

going through switched-capacitor units $\left(i_{\mathrm{SC}}\right)$ is determined by the RLC filter and has ringing. This issue commonly exists in merged-two-stage designs [33], [34].

$L_{\mathrm{par}}$ contributes to filtering and larger values are beneficial, but layouts that deliberately increase $L_{\mathrm{par}}$ often increase resistance and require extra space. Here $L_{\mathrm{par}}$ is determined by the practical value achieved in our assembly. $R_{\text {par }}$ is minimized to improve efficiency, and thus $C_{\text {filter }}$ is the only design parameter for the filter. The cutoff frequency of the RLC filter is

$$
f_{o}=\frac{1}{2 \pi \sqrt{L_{\text {par }} C_{\text {filter }}}} \text {. }
$$

The switches of the switched-capacitor stage, interconnects between the switched-capacitor stage, and PCB trace are all sources of parasitic inductance and resistance. For the vertical

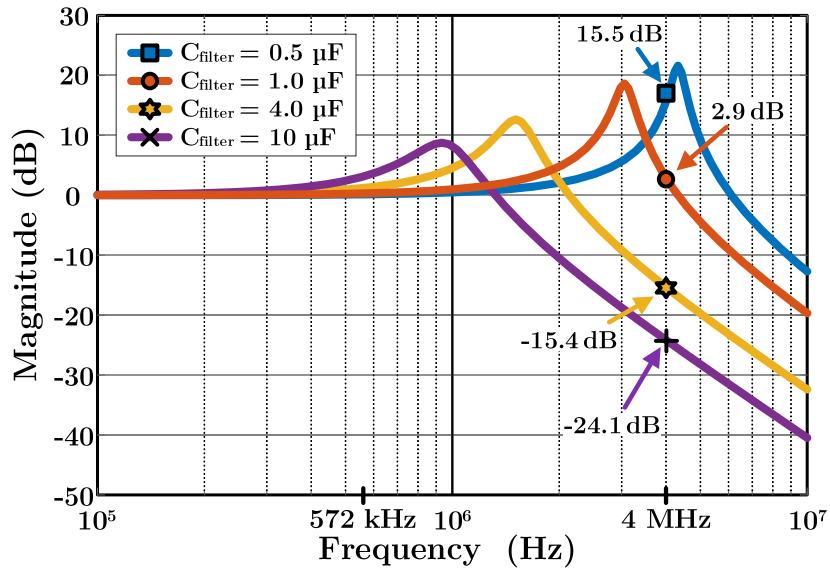

Fig. 12. Bode plot of the parasitic RLC filter magnitude response for various values of $C_{\text {filter }}$. For a buck switching frequency of $1 \mathrm{MHz}$, low values of $C_{\text {filter }}$ result in an attenuation of the high frequency current ripple. A sufficiently high value of $C_{\text {filter }}$ should be used to effectively filter the high frequency current.

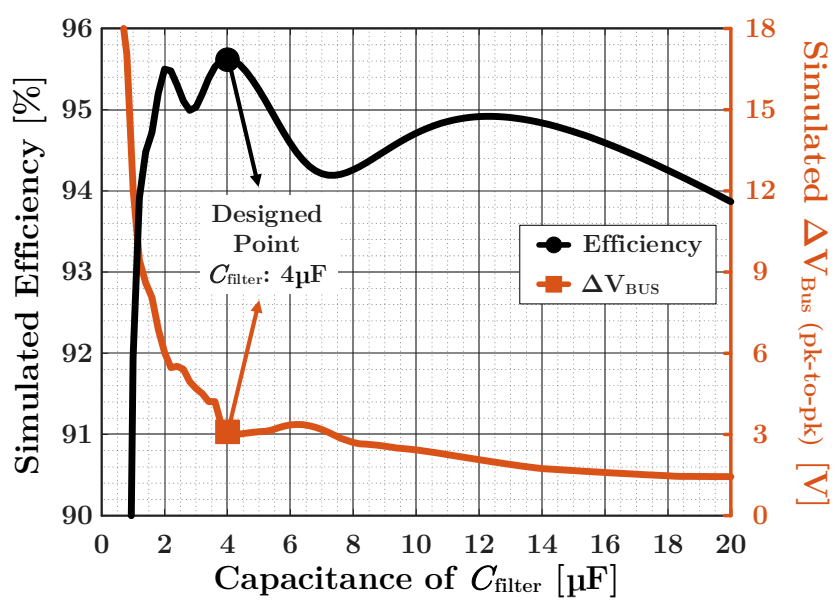

Fig. 13. Simulated efficiency of the switched-capacitor stage and intermediate bus ripple at $1 \mathrm{~V}$ and full load $(780 \mathrm{~A})$ as a function of the size of $C_{\text {filter }}$. The highest simulated efficiency is $95.6 \%$ with an intermediate bus voltage ripple of $3 \mathrm{~V}$.

stacked design introduced in Section III, the calculated parasitic inductance is $2.7 \mathrm{nH}$ and parasitic resistance is $6.1 \mathrm{~m} \Omega$. The buck switching frequency $f_{\text {Buck }}$ is $1 \mathrm{MHz}$.

Figure 12 shows a Bode plot of the magnitude response of the RLC filter, considering the buck switched current as the input and the current $i_{\mathrm{SC}}$ as the output. The response is plotted for various values of $C_{\text {filter }}$. A small filter capacitance of $0.5 \mu \mathrm{F}$ amplifies the high frequency current, which can cause increased losses. As the filter capacitance increases, the filter is able to adequately damp the current ringing. Figure 13 shows the simulated efficiency and intermediate bus voltage ripple of the LEGO-PoL design in Powersim. The simulated efficiency of the switched-capacitor stage at full load has multiple resonant peaks. As the size of $C_{\text {filter }}$ increases, the voltage ripple of the virtual intermediate bus is reduced but the efficiency decreases due to charge sharing loss. $C_{\text {filter }}$ is selected to be $4.0 \mu \mathrm{F}$ to achieve high efficiency (95.6\%) while maintaining a low virtual intermediate bus voltage ripple $(3 \mathrm{~V})$. 

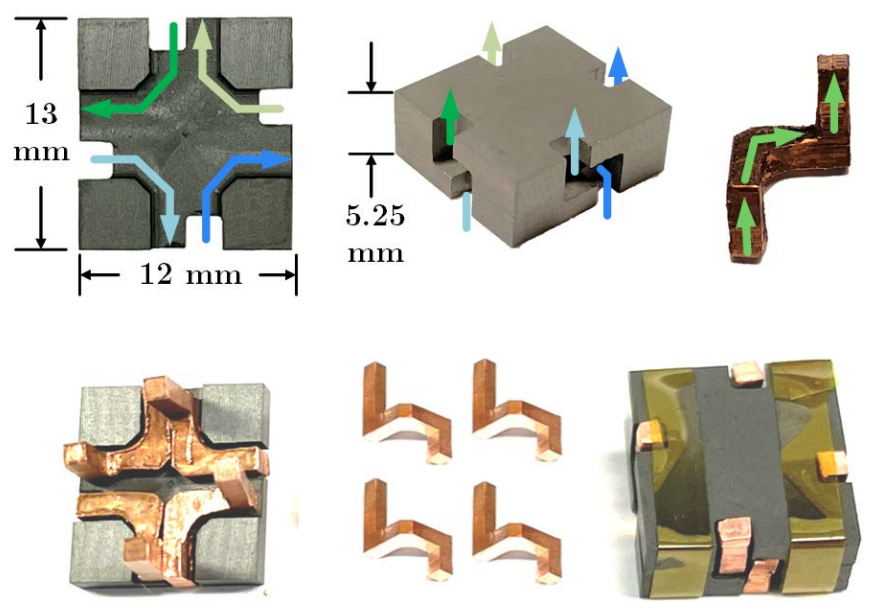

Fig. 14. Picture of the vertical four-phase coupled inductor magnetic core. Four machined copper windings make a $90^{\circ}$ rotation within the core and deliver current from bottom to top. Cutouts in the core shorten the conduction path and facilitate the winding placement within the core.

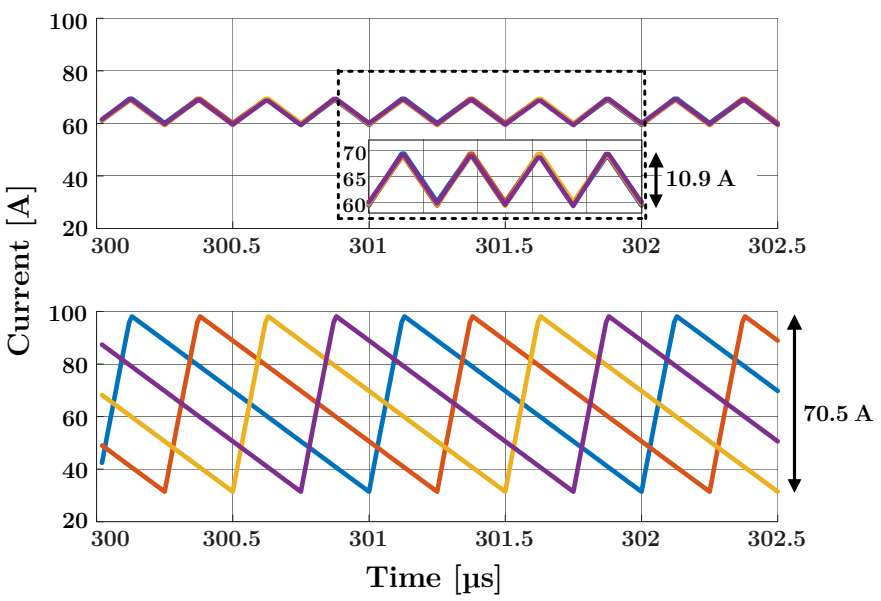

Fig. 15. Simulated waveforms of the multiphase buck converter with a coupled inductor (top) and four uncoupled inductors (bottom). The coupled inductor reduces the peak-to-peak phase current ripple from $70.5 \mathrm{~A}$ to $10.9 \mathrm{~A}$ while maintaining the same transient performance.

\section{Parallel Interleaved Buck Stage}

Three parallel-connected four-phase buck units equally share $780 \mathrm{~A}$ of output current. Each individual phase delivers $65 \mathrm{~A}$. The peak virtual intermediate bus voltage is $9.5 \mathrm{~V}$ (nominally $8 \mathrm{~V}$, with a peak-to-peak voltage ripple of $3 \mathrm{~V}$ ). The reduced stress enables the use of low voltage high current semiconductor devices and small magnetics. State-ofthe-art control strategies for multiphase buck converters can be adopted. In a traditional 12-phase buck converter design, the controller needs to balance the current of all phases. Due to automatic current sharing, the controller only needs to balance the current of the four phases within each submodule. This unique feature allows LEGO-PoL architecture to be scaled to a very high current without adding significant control complexity. This is a key advantage of LEGO-PoL compared to traditional two-stage intermediate bus architectures with numerous parallel units, which require active control for current balancing.
TABLE I

COMPARISON BETWEEN DISCRETE AND COUPLED INDUCTORS

\begin{tabular}{cccc}
\hline Symbol & Parameter & Discrete & Coupled \\
\hline$V_{I N}$ & Buck Stage Input Voltage & \multicolumn{2}{c}{$8 \mathrm{~V}$} \\
\hline$V_{O U T}$ & Output Voltage & \multicolumn{2}{c}{$1 \mathrm{~V}$} \\
\hline$f_{\text {Buck }}$ & Switching Frequency & \multicolumn{2}{c}{$1 \mathrm{MHz}$} \\
\hline$L_{\ell}$ & Phase Leakage Inductance & $85 \mathrm{nH}$ & $12.4 \mathrm{nH}$ \\
\hline$L_{t r}$ & System Transient Inductance & $7.08 \mathrm{nH}$ & $1.03 \mathrm{nH}$ \\
\hline$R_{d c}$ & Phase dc Resistance & $0.39 \mathrm{~m} \Omega$ & $0.09 \mathrm{~m} \Omega$ \\
\hline$P_{c}$ & System Core Loss & $1.6 \mathrm{~W}$ & $0.45 \mathrm{~W}$ \\
\hline$I_{\text {sat }}$ & Saturation Current & $86 \mathrm{~A}$ & N/A \\
\hline$\Delta i_{p}$ & Phase Current Ripple & $10.3 \mathrm{~A}$ & $10.9 \mathrm{~A}$ \\
\hline $\mathrm{V}$ & Total Volume & $4.24 \mathrm{~cm}^{3}$ & $2.45 \mathrm{~cm}^{3}$ \\
\hline \multicolumn{4}{c}{}
\end{tabular}

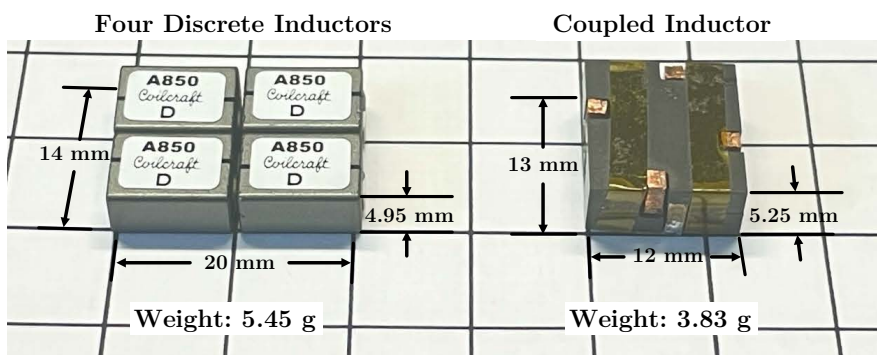

Fig. 16. Comparison of the coupled inductors with four discrete Coilcraft SLR1050A $85 \mathrm{nH}$ discrete inductors. A comparison of the two solutions is presented in Table I. The coupled inductor enables a smaller leakage inductance and overall system transient inductance, lower dc resistance per phase, and lower core loss. The two options have similar phase current ripples. The volume of the three coupled inductors is only $57.7 \%$ of that of the twelve discrete inductors, with only $25 \%$ of the dc resistance.

Figure $7 \mathrm{c}$ shows the component placement of the buck stage. Two $5 \mathrm{~mm} \times 6 \mathrm{~mm}$ DrMOSes are placed on the top and two are placed on the bottom. Each phase is designed to have the same PCB pattern from the input node to each of the coupled inductor interconnect nodes to minimize the current mismatch. Capacitors, as designed in Section III-B, are placed in the center of the board to filter the high frequency current.

Figure $7 \mathrm{~d}$ shows the PCB layout of the interposer board. The interposer board decouples the design constraints of the buck board and the coupled inductor. Interconnect $\mathrm{A}$ is for the buck PCB connection, while interconnect $\mathrm{B}$ is for the coupled inductor. The interposer board is 4-layer, $2 \mathrm{oz}$ copper thickness, and $0.6 \mathrm{~mm}$ board thickness.

\section{Vertical Four-Phase Coupled Inductor}

A coupled inductor can reduce the steady-state current ripple in each phase of the buck stage, and achieve fast dynamic performance with small leakage inductance [26]. In the 3D packaged prototype, three four-phase coupled inductors link the buck stage and output board with vertical windings. Figure 14 shows the coupled inductor, which is fabricated with Ferroxcube 3F4 MnZn ferrite. The footprint of the core is $13 \mathrm{~mm} \times 12 \mathrm{~mm}$, and its height is $5.25 \mathrm{~mm}$. This design is optimized to minimize the core and winding losses at an operating point of $20 \mathrm{~A}$ per phase. The designed core has higher density and lower dc resistance than the design presented in [3]. To enable vertical power delivery, the machined 


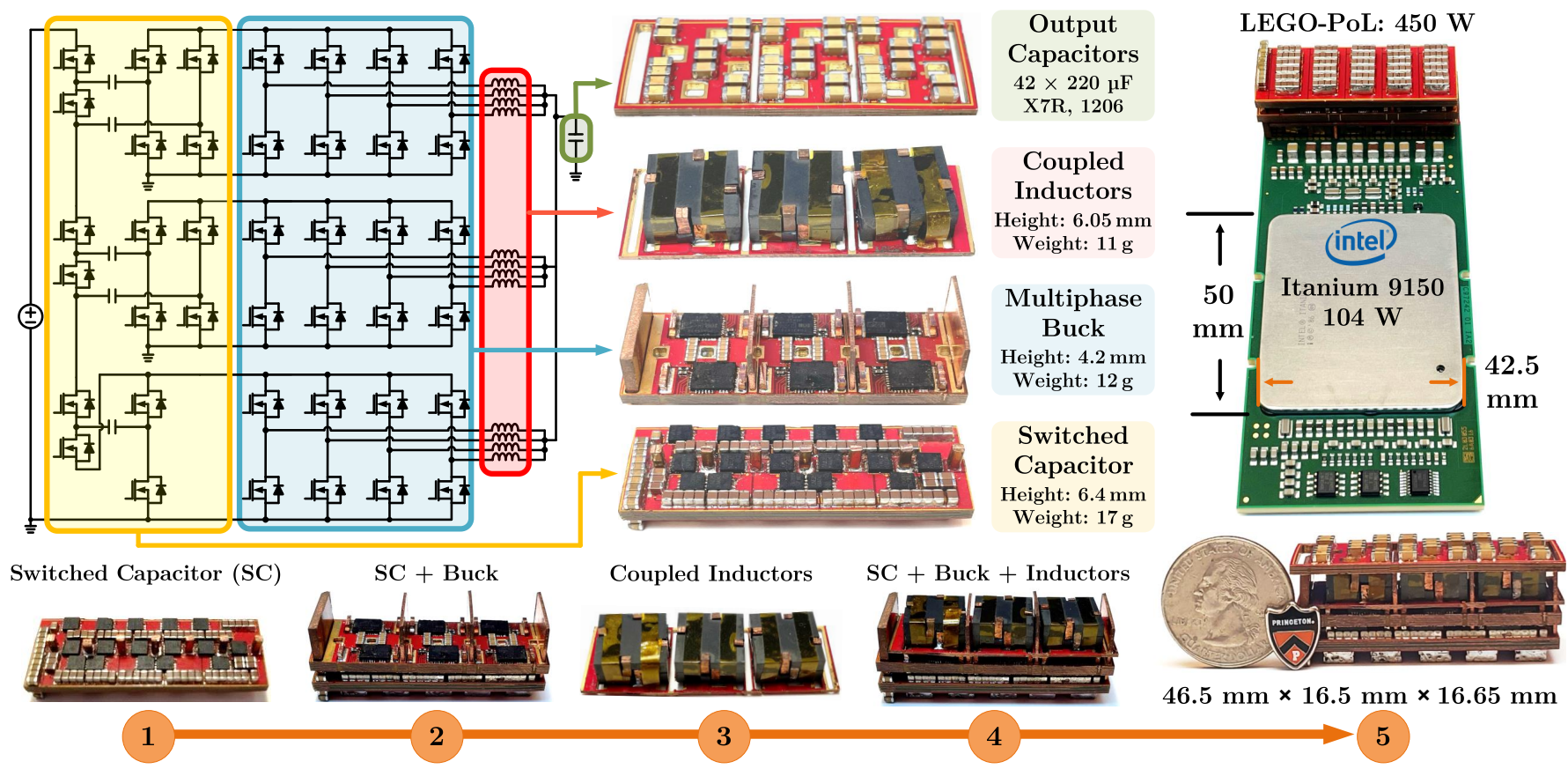

Fig. 17. Simplified schematic of the vertical stacked LEGO-PoL converter highlighting the switched-capacitor stage, buck stage, inductors, and output capacitors (left); assembly procedure of the vertical stacked LEGO-PoL converter (bottom); fully assembled converter next to a US Quarter and an Intel Itanium $9150 \mathrm{CPU}$. The power stage area of the prototype is $46.5 \mathrm{~mm} \times 16.5 \mathrm{~mm}=767.25 \mathrm{~mm}^{2}$. The height of the prototype is $16.65 \mathrm{~mm}$. The current density is $1.017 \mathrm{~A} / \mathrm{mm}^{2}$ at $780 \mathrm{~A}$ and the power density is $1000 \mathrm{~W} / \mathrm{in}^{3}$ at $1 \mathrm{~V}$ and $780 \mathrm{~A}$ with a maximum junction temperature of $94^{\circ} \mathrm{C}$ under liquid cooling.

copper windings enter from the bottom of the core, make a $90^{\circ}$ rotation within the core, and exit from the top of the core to the output motherboard. The empty area within the core between windings can be adjusted to control the leakage flux path, which determines the transient and ripple performance [31]. An extended discussion about the coupled inductor design and optimization parameters is provided in [32].

Table I lists the key parameters of the four-phase buck units with the coupled inductors. The leakage inductance per phase is $12.4 \mathrm{nH}$, to achieve a targeted maximum output current slew rate of $5 \mathrm{~A} / \mathrm{ns}$. The overall system transient inductance is $1.03 \mathrm{nH}$, as there are 12 total phases amongst the three buck units. The peak-to-peak phase current ripple of the buck units is $10.9 \mathrm{~A}$ with the coupled inductor. To achieve the transient current speed using uncoupled discrete inductors, four $12.4 \mathrm{nH}$ discrete inductors must be used. This would yield a $70.5 \mathrm{~A}$ peak-to-peak phase current ripple, as simulated in Fig. 15. This coupled inductor is designed to be able to handle a phase current mismatch of $10 \%$ of the full load current $65 \mathrm{~A}$ per phase) without saturation. If the phase currents are well balanced, the coupled inductor will not saturate.

Figure 16 compares the size of the coupled inductor against four Coilcraft SLR1050A $85 \mathrm{nH}$ discrete inductors, which achieve a similar peak-to-peak phase current ripple as the coupled inductor. A more detailed comparison of the two solutions is presented in Table I. The coupled inductor achieves a much lower leakage inductance while maintaining a similar peak-to-peak phase current ripple as the discrete inductor solution. It also has a lower dc resistance and lower core loss. The volume of the coupled inductor is only $57.7 \%$ of that of the four discrete inductors.

\section{E. Output Board and Output Capacitor Design}

Figure 7e shows the PCB layout of the output board. The output board combines the current and hosts the output capacitors. Outside of the power stage area, terminal connections are placed to connect the converter to electronic loads. Each module has four terminals, labeled "interconnect B" for the four-phase coupled inductor. The remainder of the space is used for $14 \times 1206$ capacitors per module. In the prototype, $220 \mu \mathrm{F}$ capacitors are used to satisfy a $\pm 2 \%$ output voltage ripple requirement. The effective total converter output capacitance is $5.75 \mathrm{mF}$ at an output voltage of $1 \mathrm{~V}$.

Figure $7 \mathrm{f}$ shows the full 3D assembly drawing of the prototype. The switched-capacitor stage and the buck stage each occupy about one-half of the system volume. Power is vertically delivered from $48 \mathrm{~V}$ on the bottom to $1 \mathrm{~V}$ on the top. The overall height of the prototype is $16.65 \mathrm{~mm}$.

\section{EXPERIMENTAL VERIFICATION}

A $48 \mathrm{~V}$ to $1 \mathrm{~V}, 780$ A vertical stacked LEGO-PoL converter was fabricated and tested. Figure 17 shows the 3D structure and assembly procedure of the prototype. The input voltage range is from $36 \mathrm{~V}$ to $54 \mathrm{~V}$, and the output voltage range is from $0.8 \mathrm{~V}$ to $1.5 \mathrm{~V}$. Three submodules were used, as per the schematic in Fig. 6. Table II lists the key power stage components of this design. The switches in the switchedcapacitor units are implemented as MOSFETs. The switches in the multiphase buck units are implemented as low voltage DrMOS devices. The same type of capacitors was used for $C_{1}-C_{5}$. Due to different bias voltages, the derated capacitance of each flying capacitor varies. For the filter capacitance, 
TABLE II

Key Components of the Vertical LEGO-PoL Prototype

\begin{tabular}{|c|c|c|c|}
\hline Symbol & \multicolumn{3}{|c|}{ Component } \\
\hline$Q_{1} \& Q_{6}$ & \multicolumn{3}{|c|}{ Infineon BSZ010NE2LS5 $(25 \mathrm{~V}, 212 \mathrm{~A})$} \\
\hline$Q_{2}-Q_{5}$ & \multicolumn{3}{|c|}{ Infineon BSZ0501NSI (30 V, $123 \mathrm{~A})$} \\
\hline$Q_{S 1}-Q_{S 10}$ & \multicolumn{3}{|c|}{ Infineon BSZ010NE2LS5 (25 V, $212 \mathrm{~A})$} \\
\hline$Q_{H} \& Q_{L}$ & \multicolumn{3}{|c|}{ Infineon TDA21472 DrMOS (16 V, $70 \mathrm{~A})$} \\
\hline$C_{1}-C_{5}$ & \multicolumn{3}{|c|}{ TDK $4.7 \mu \mathrm{F}, 0805$, X7R MLCC $(50 \mathrm{~V})$} \\
\hline$C_{\text {filter }}$ & \multicolumn{3}{|c|}{ Kemet $0.22 \mu \mathrm{F}, 0603, \mathrm{X} 7 \mathrm{R}$ MLCC (25 V) } \\
\hline Controller & \multicolumn{3}{|c|}{ Texas Instruments TMS320F28388D } \\
\hline Symbol & Bias Voltage & Number & Effective Size \\
\hline$C_{1}$ & $40 \mathrm{~V}$ & 59 & $47.2 \mu \mathrm{F}$ \\
\hline$C_{2}$ & $32 \mathrm{~V}$ & 57 & $62.7 \mu \mathrm{F}$ \\
\hline$C_{3}$ & $24 \mathrm{~V}$ & 58 & $82.0 \mu \mathrm{F}$ \\
\hline$C_{4}$ & $16 \mathrm{~V}$ & 59 & $140 \mu \mathrm{F}$ \\
\hline$C_{5}$ & $8 \mathrm{~V}$ & 68 & $257 \mu \mathrm{F}$ \\
\hline$C_{\text {filter }}$ & $8 \mathrm{~V}$ & 24 & $4.0 \mu \mathrm{F}$ \\
\hline
\end{tabular}

$24 \times 0.22 \mu \mathrm{F} 0603$ size capacitors per module are used and the effective $C_{\text {filter }}$ is $4.0 \mu \mathrm{F}$ at $8 \mathrm{~V}$ bias voltage and $4 \mathrm{MHz}$ frequency.

\section{A. Experimental Setup}

Figure 18 shows the experimental setup to characterize the performance of the vertical stacked LEGO-PoL converter. All of the necessary equipment is placed in a standard $1 \mathrm{U}$ server rack setup. A Tektronix MDO4140C Oscilloscope is used to measure operation waveforms. Five Agilent 34401A digital multimeters are used to take automated measurements of the input voltage, input current, output voltage, output current, and DrMOS junction temperature. A BK Precision $91173 \mathrm{~kW}$, $80 \mathrm{~V}, 120 \mathrm{~A}$ dc power source is used. Rideon RSN-50 and Rideon RSC-1000 current shunts are used for input and output current measurement. Two electronic loads, a Chroma 63103A 240 A load and a Chroma 63203600 A load, are used. The vertical stacked LEGO-PoL prototype was tested under two different cooling conditions: air cooling (Fig. 18b) and liquid cooling (Fig. 18c). Two 36 CFM fans are used for the air cooling. Mineral oil is used for the liquid cooling, and two 36 CFM fans and a pump are used to circulate the liquid.

\section{B. Operation and Performance}

Figure 19 shows the measured waveforms of the switchedcapacitor stage at a $48 \mathrm{~V}$ input voltage, $1 \mathrm{~V}$ output voltage, and an output current of $780 \mathrm{~A}$. The input voltage is shown on top, and the differential voltage across $C_{2}$ and $C_{4}$, as well as the leftmost node voltage of $C_{5}$ (denoted $V_{C_{F 5}}$ on the schematic of Fig. 6), are shown below the input voltage.

Figure 20 shows the waveforms of the intermediate bus voltages of each module at the same operating condition as above. The dc value of each of the three bus voltages is very close, further verifying the voltage balancing of the LEGOPoL converter. Due to the different dc bias voltage of the flying capacitors (listed in Table II), each module has a different intermediate bus voltage ripple. Module \#1 has the highest

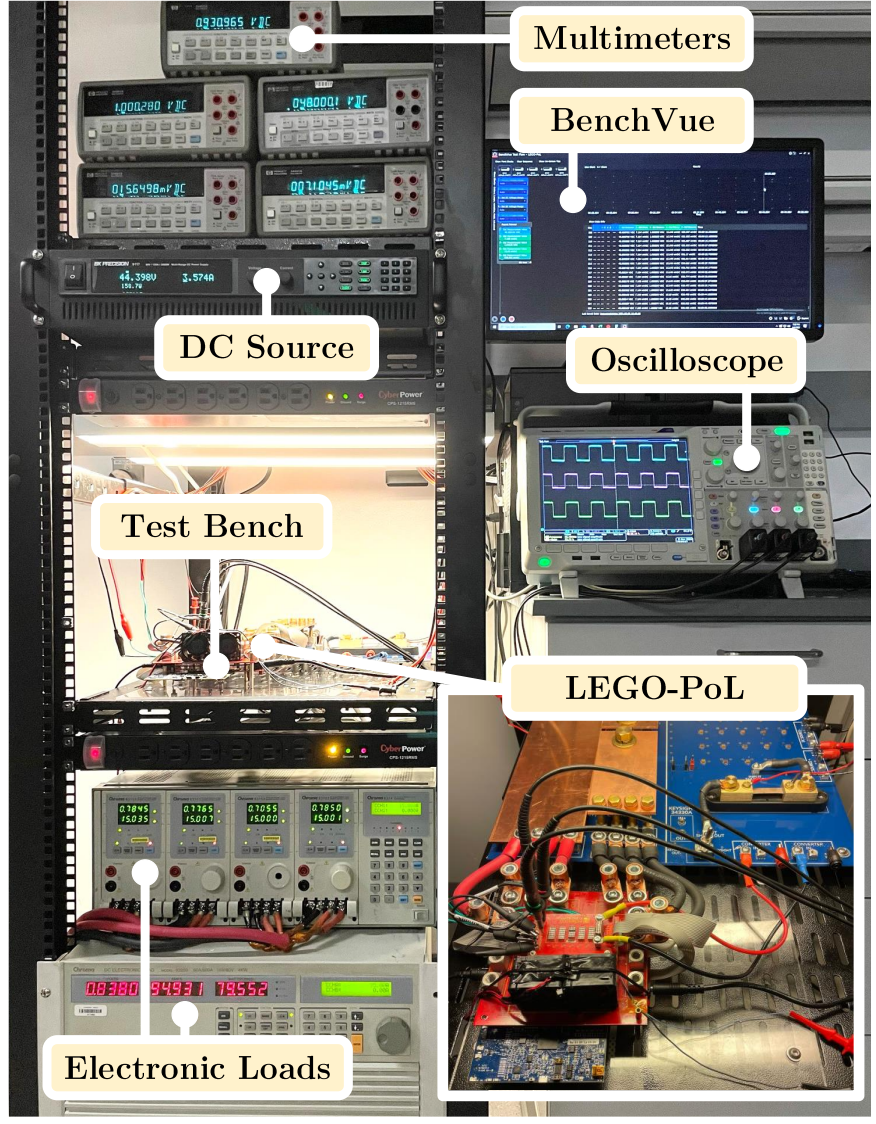

(a)

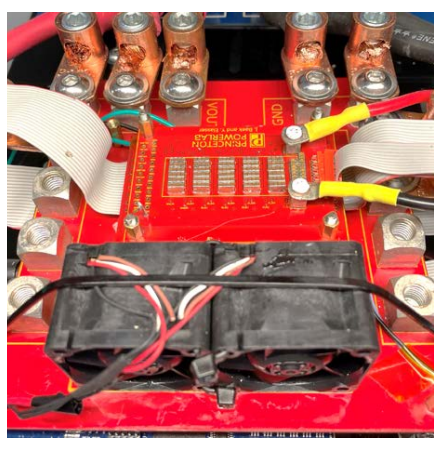

(b)

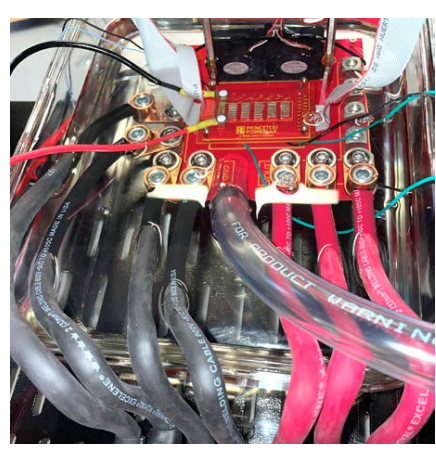

(c)
Fig. 18. (a) Picture of the experimental setup. Digital multimeters are used to take automated measurements via the BenchVue software. An interface PCB is used to connect the device under test to the DC power source and the electronic loads, as well as house the measurement shunts; (b) Zoomed in view of the test bench for air cooling operation; (c) Zoomed in view of the test bench for liquid cooling operation. The converter is placed in a container filled with mineral oil. A pump and two fans are used to circulate the oil.

voltage ripple due to the higher bias voltage, and module \#3 has the lowest voltage ripple.

Figure 21 shows the switch node voltages of each of the four phases of the second buck module. The envelope of the switch nodes is equal to $V_{B U S 2}$, which is the input voltage of the buck unit. The four phases are interleaved, with a duty cycle of $15.7 \%$. The switching frequency is $1 \mathrm{MHz}$.

Figure 22 shows the output voltage and virtual intermediate bus voltage waveforms in response to a buck switch duty ratio change from $15 \%$ to $20 \%$ at an output load current of $150 \mathrm{~A}$. 


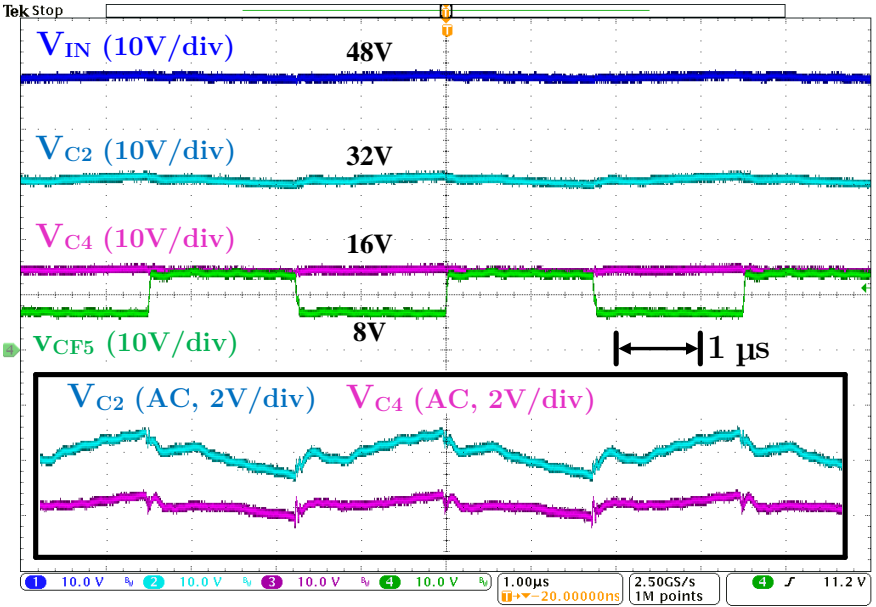

Fig. 19. Measured waveforms of the switched-capacitor stage at $48 \mathrm{~V}$ input, $1 \mathrm{~V} / 780$ A output. The series-stacked switched-capacitor modules evenly split $48 \mathrm{~V}$ input voltage into three $16 \mathrm{~V}$ voltage domains. $C_{2}$ has a higher voltage ripple than $C_{4}$ due to higher dc bias voltage.

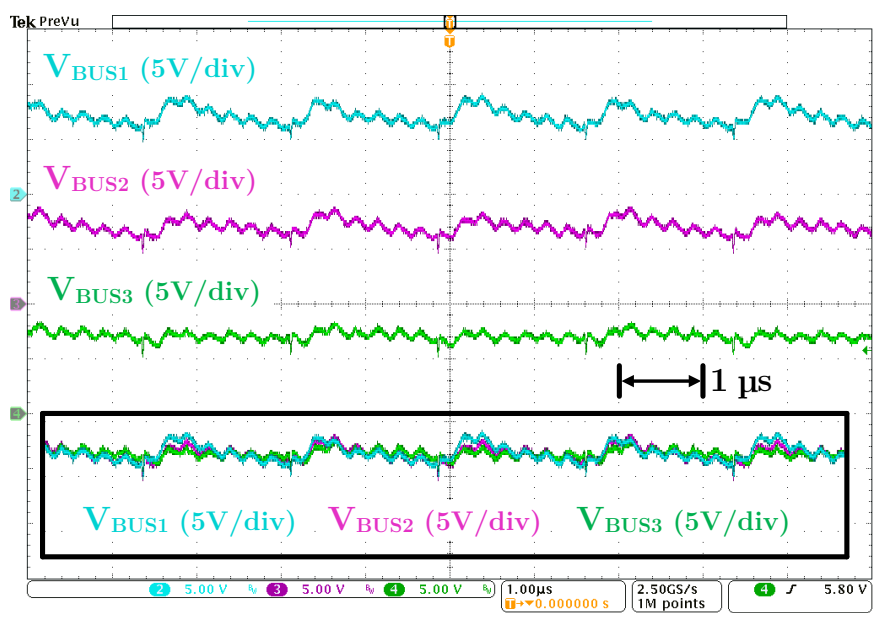

Fig. 20. Measured waveforms of three bus voltages at $48 \mathrm{~V}$ input, $1 \mathrm{~V} / 780 \mathrm{~A}$ output. The three virtual intermediate bus voltages are automatically balanced.

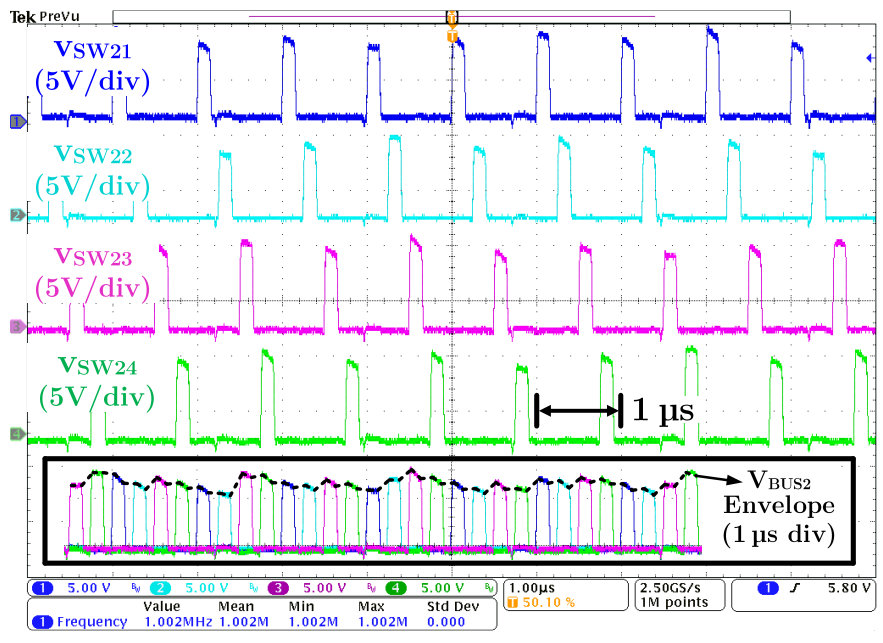

Fig. 21. Measured waveforms of switch nodes of a four-phase buck module at $48 \mathrm{~V}$ input, $1 \mathrm{~V} / 780$ A output. The four phases are interleaved. The envelope of the switch nodes is equal to the virtual intermediate bus voltage.

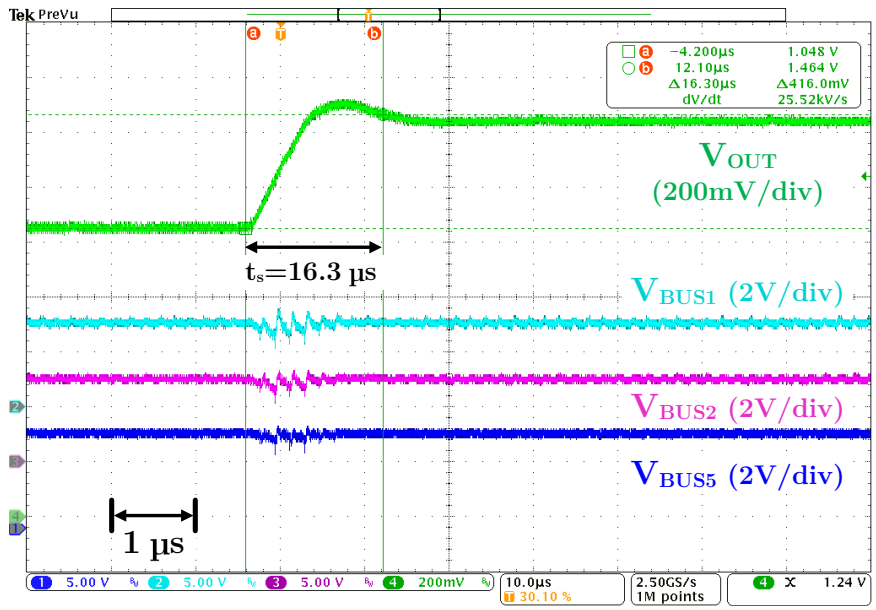

Fig. 22. Measured transient waveforms with an open-loop buck duty ratio step from $15 \%$ to $20 \%$ at $150 \mathrm{~A}$. The output voltage steps from $1.048 \mathrm{~V}$ to $1.464 \mathrm{~V}$ within $16.3 \mu \mathrm{s}$.

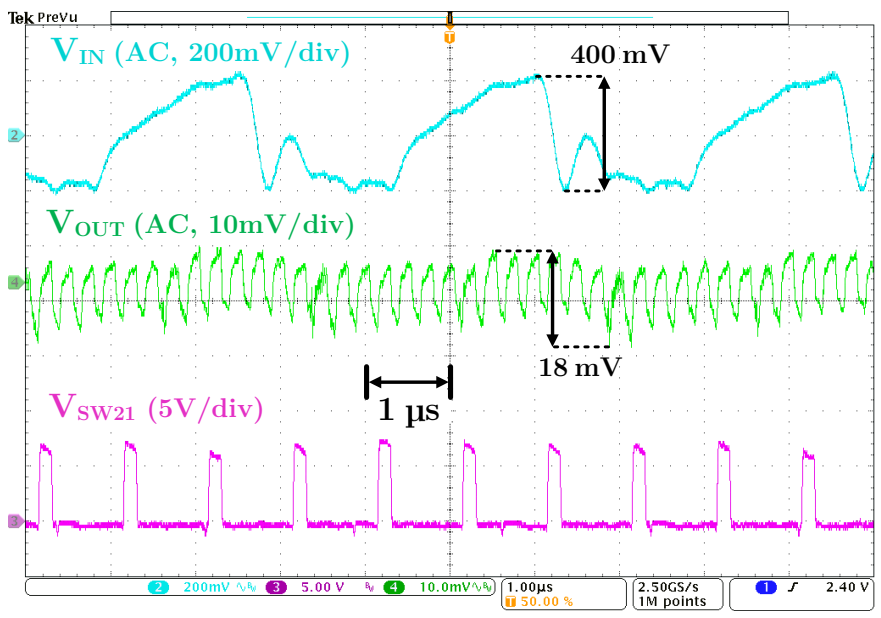

Fig. 23. Measured voltage ripples at $48 \mathrm{~V}$ input, $1 \mathrm{~V} / 780 \mathrm{~A}$ output.

The output voltage settles to within $2 \%$ of its expected value in $16.3 \mu \mathrm{s}$. The virtual intermediate bus voltages remain stable, with increased ripple during the transition as the output capacitors are being charged to the new output voltage level. The switched-capacitor stage of the LEGO-PoL converter operates as a dc transformer like a traditional hybrid-switched-capacitor stage. Figure 23 shows the input and output voltage ripple waveforms at $48 \mathrm{~V}$ input and $1 \mathrm{~V} / 780$ A output. The steady state output voltage ripple is $18 \mathrm{mV}$ with $5.75 \mathrm{mF}$ output capacitance. The input capacitor voltage ripple is $400 \mathrm{mV}$.

Figure 24 shows a closed-loop transient test for a $50 \%$ load step. A classic voltage mode feedback PI controller is used for this experiment. The three virtual intermediate bus voltages and output voltage in response to an output current load step between $50 \mathrm{~A}$ and $450 \mathrm{~A}$ are measured. The mergedtwo-stage operation maintains stable intermediate bus voltage without a large decoupling capacitor, with expected ripple due to the increase in output load current. Due to the limited controller bandwidth, a $120 \mathrm{mV}$ peak-to-peak voltage excursion is observed during the transient. Advanced control methods, 


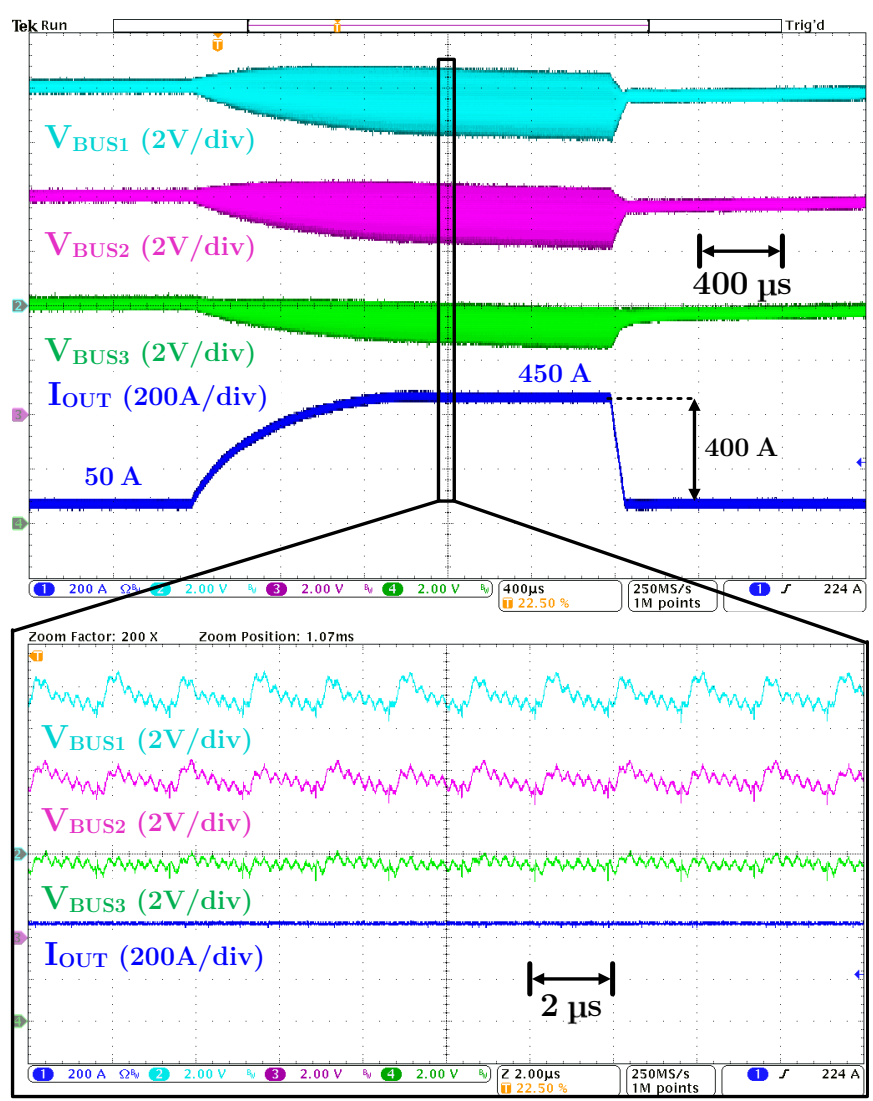

(a)

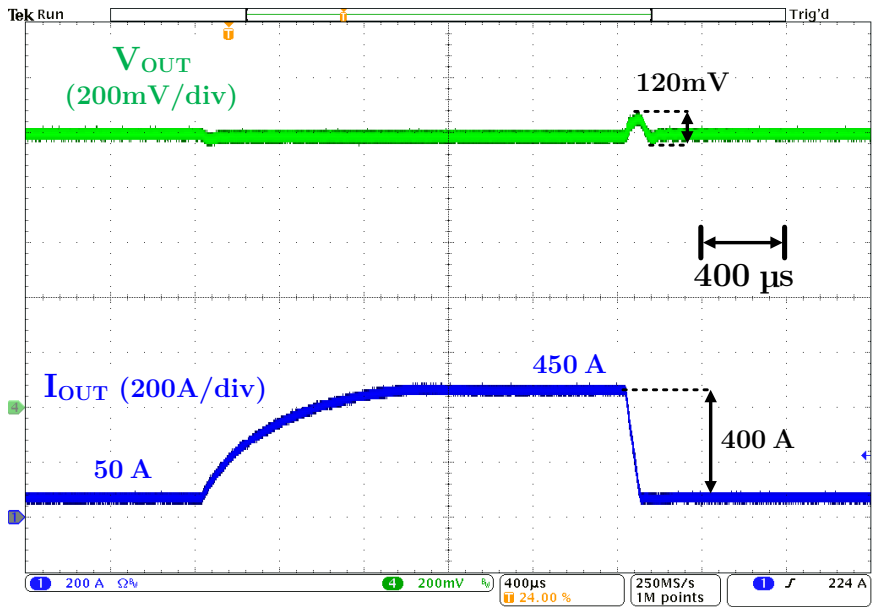

(b)

Fig. 24. Measured transient waveforms with a load current step between $50 \mathrm{~A}$ and 450 A (50\% load step). (a) Three intermediate bus voltages. (b) Output voltage. A classic voltage-mode digital PI feedback loop was implemented in a microcontroller (TMS320F28388D) for this test. The total output capacitance is $5.75 \mathrm{mF}$. Demonstrating extreme transient performance of the LEGO-PoL architecture is beyond the scope of this paper.

such as current mode control, can significantly improve the transient performance. Demonstrating the extreme transient performance of the converter is beyond the scope of this paper.

Figure 25 and 26 summarizes the system efficiency of the LEGO-PoL converter with air cooling and liquid cooling. Measurements were taken at four different output voltage conditions: $0.8 \mathrm{~V}, 1.0 \mathrm{~V}, 1.2 \mathrm{~V}$, and $1.5 \mathrm{~V}$. The input and

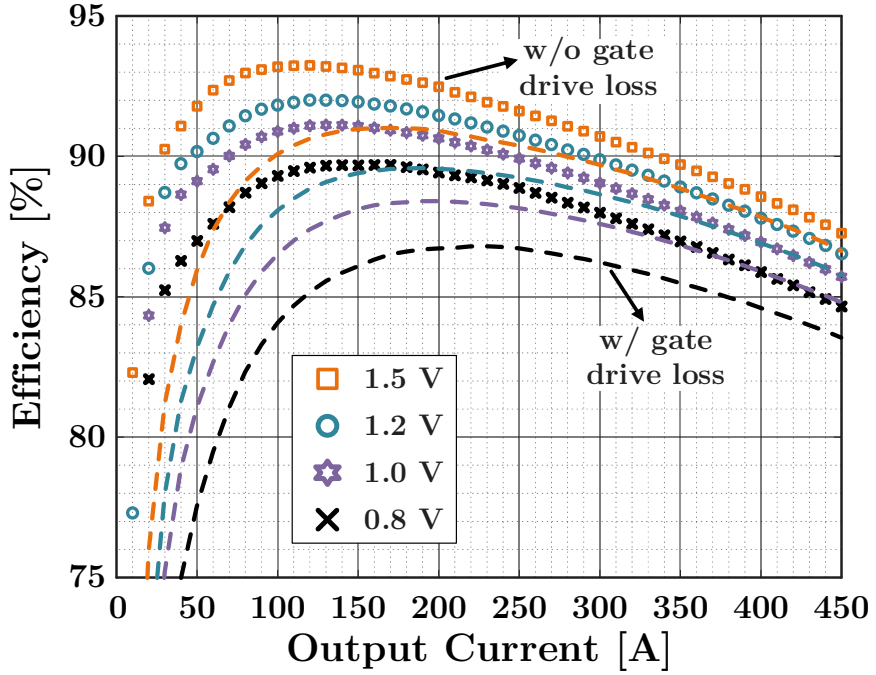

Fig. 25. Measured efficiency at $48 \mathrm{~V}$ input and different output voltages with air cooling and with and without gate drive loss. Two 36 CFM fans are used. The DrMOS junction temperature is kept below $100^{\circ} \mathrm{C}$.

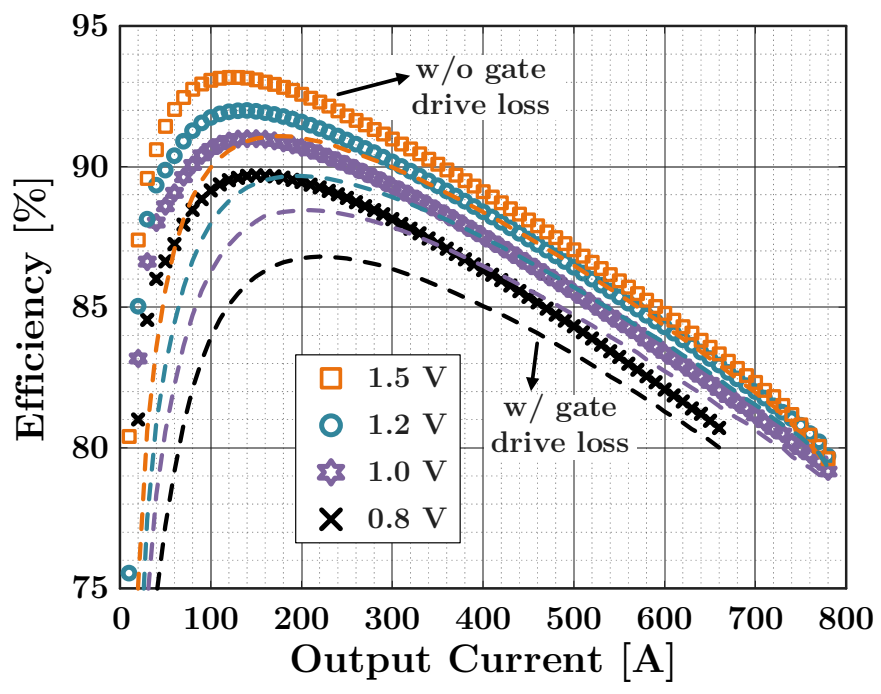

Fig. 26. Measured efficiency at $48 \mathrm{~V}$ input and different output voltages with liquid cooling and with and without gate drive loss. The converter is submerged in mineral oil, and a pump and two 36 CFM fans are used to circulate the liquid. The DrMOS junction temperature is kept below $100^{\circ} \mathrm{C}$.

output voltages were measured right at the input and output capacitors. Due to the voltage drop between the output of the converter and the electronic loads, the measurement data for the $0.8 \mathrm{~V}$ output voltage condition stops at $660 \mathrm{~A}$. The data for the other three conditions are provided across the full operating range in $10 \mathrm{~A}$ intervals. The switched-capacitor switching frequency is $286 \mathrm{kHz}$ and the buck switching frequency is $1 \mathrm{MHz}$. The converter can achieve a $93.2 \%$ peak efficiency at $V_{\text {out }}=1.5 \mathrm{~V}$ and $I_{\text {out }}=130 \mathrm{~A}$, and a $91.1 \%$ peak efficiency at $V_{\text {out }}=1.0 \mathrm{~V}$ and $I_{\text {out }}=160 \mathrm{~A}$. At $780 \mathrm{~A}$, the efficiency of the converter at $V_{\text {out }}=1.5 \mathrm{~V}$ is $79.6 \%$ and $79.2 \%$ at $V_{\text {out }}=1.0 \mathrm{~V}$. The maximum power rating of the converter in air cooling is 450 A with the DrMOS junction temperature below $100^{\circ} \mathrm{C}$. The gate drive loss of the prototype is estimated as $5.02 \mathrm{~W}$ (switched-capacitor stage: $2.02 \mathrm{~W}$, buck stage: $3 \mathrm{~W}$ ). 


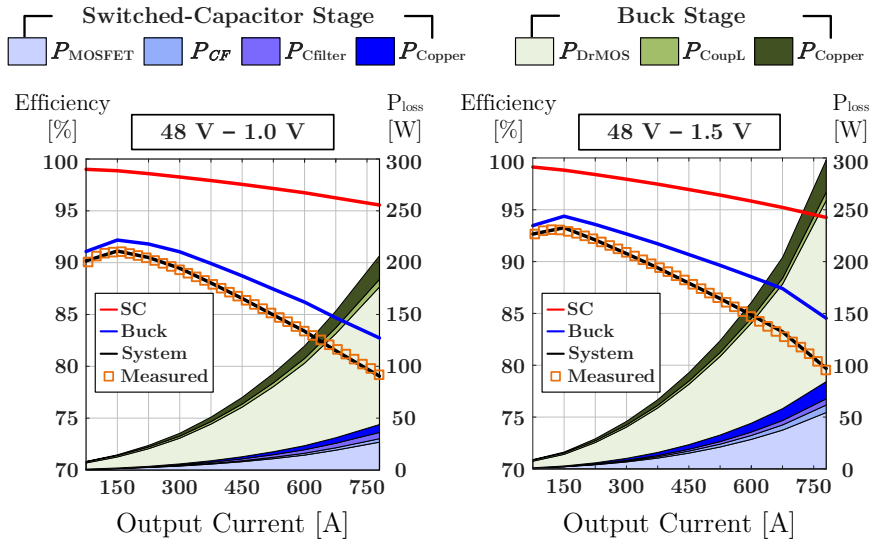

Fig. 27. Loss breakdown and calculated efficiencies of the switched-capacitor stage, buck stage, and total system at $1.0 \mathrm{~V}$ and $1.5 \mathrm{~V}$ output conditions. $P_{\text {Mosfet }}, P_{C}, P_{C \text { filter }}$, and $P_{\text {Copper }}$ are the loss of MOSFETs, switchedcapacitors, filter capacitors, and copper trace including connectors and PCB in the switched-capacitor stage. $P_{\text {DrMos }}, P_{\text {CoupL }}$, and $P_{\text {Copper }}$ are the loss of DrMOS, coupled inductors, and copper trace in the buck stage.
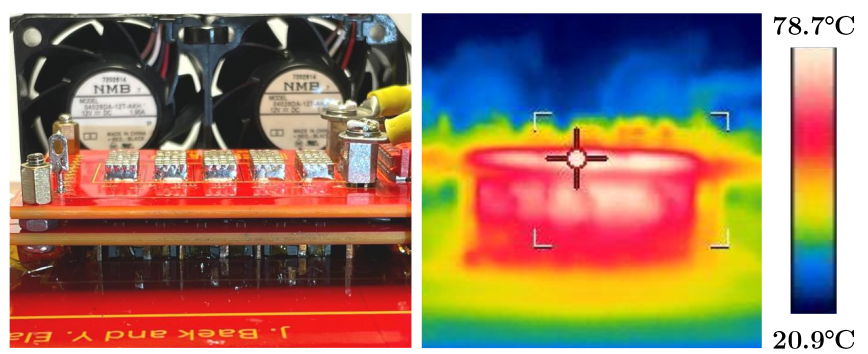

(a)

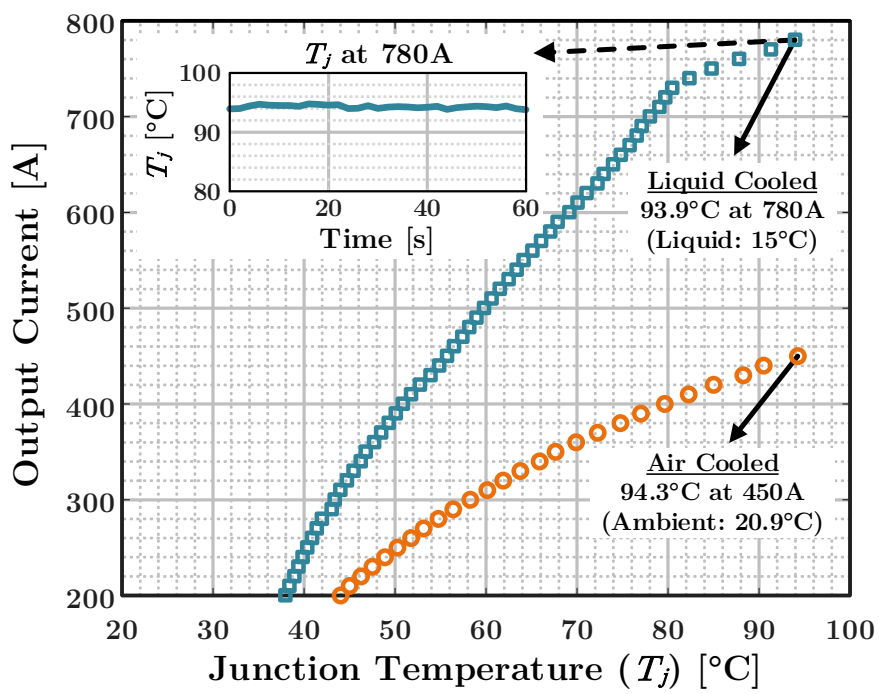

(b)

Fig. 28. (a) Thermal image of the vertical stacked LEGO-PoL converter. The thermal image was measured at $20.9^{\circ} \mathrm{C}$ ambient temperature with two 36 CFM fans. (b) Measured DrMOS junction temperature (from $T_{j}$ sensing pin) with air cooling and liquid cooling. The junction temperature is stable at 780 A output current with liquid cooling.

A detailed theoretical loss breakdown is provided in Fig. 27 for $1.0 \mathrm{~V}$ and $1.5 \mathrm{~V}$ output voltage. The loss breakdown was performed with the experimental duty ratio of the buck stage and junction temperature of DrMOS in Fig. 28b. Losses from the switched-capacitor stage include loss from the MOSFETs, the flying-capacitors, the filter capacitors, and the copper traces. Loss from the buck stage includes loss from the DrMOS, the coupled-inductor (both core loss and conduction loss), and the copper traces. The DrMOS switching and conduction loss dominates the loss of the overall system due to its high-switching-frequency operation and high output current. The switched-capacitor stage maintains high efficiency (above $95.5 \%$ ) throughout the entire load range at $1 \mathrm{~V}$ output voltage condition. The overall system efficiency curve mirrors the shape of the buck efficiency curve, with a larger slope as the load current increases due to increased conduction loss. The converter achieves peak efficiency at around $20 \%$ full power, dominated by the efficiency curves of the buck stage.

Without liquid cooling, the maximum output current of the system is $450 \mathrm{~A}$. Figure 28a shows a thermal image of the converter at $V_{\text {out }}=1.5 \mathrm{~V}$ and $I_{\text {out }}=450 \mathrm{~A}$. Two 36 CFM fans are used, and the PCBs reach a temperature of $78.7^{\circ} \mathrm{C}$. Figure $28 \mathrm{~b}$ shows a graph of the DrMOS junction temperature (using the built-in temperature sensing pin) for both the air cooled and liquid cooled operation at $V_{\text {out }}=1.5 \mathrm{~V}$. The junction temperature reaches $94.3^{\circ} \mathrm{C}$ at $I_{\text {out }}=450 \mathrm{~A}$. By employing liquid cooling, the junction temperature of the DrMOS reaches $93.9^{\circ} \mathrm{C}$ at $I_{\text {out }}=780 \mathrm{~A}$.

\section{Performance Comparison}

Table III compares key metrics of the vertical stacked LEGO-PoL converter with other state-of-the-art $48 \mathrm{~V}$-to-1 V point-of-load voltage regulator designs. The converter presented in this work achieves the highest reported output current capability at either $450 \mathrm{~A}$ with air cooling or 780 A with liquid cooling. This work achieves both the highest power density and the highest current area density, at $577 \mathrm{~W} / \mathrm{in}^{3}$ and $0.587 \mathrm{~A} / \mathrm{in}^{2}$ for air cooling and $1000 \mathrm{~W} / \mathrm{in}^{3}$ and $1.017 \mathrm{~A} / \mathrm{in}^{3}$ for liquid cooling. This is the first demonstration of a $48 \mathrm{~V}$ to $1 \mathrm{~V}$ point-of-load $\mathrm{CPU}$ voltage regulator to achieve over a $1 \mathrm{~A} / \mathrm{mm}^{2}$ current area density and the first to achieve $1,000 \mathrm{~W} / \mathrm{in}^{3}$ power density. This work achieves a peak efficiency of $91.1 \%$ and a full load efficiency of $85.7 \%$ with air cooling (79.2\% with liquid cooling), which is comparable to other high-density designs. The switching frequency of the voltage regulation stage is $1 \mathrm{MHz}$, among the highest for a $48 \mathrm{~V}$ CPU voltage regulator demonstration. The coupled inductors enable the smallest transient inductance and lowest inductive energy storage per watt (defined as the total $\frac{1}{2} L I^{2}$ energy storage divided by the output power rating $P$, ignoring the current ripple) for this work when compared to other work.

Table III is visualized in Fig. 29 and Fig. 30. The switching frequency is represented by a color gradient. This work achieves the highest current area density while maintaining state-of-the-art peak efficiency, achieves the highest power density while maintaining high full-load efficiency, and switches at a high frequency of $1 \mathrm{MHz}$ with interleaving.

\section{Discussions AND FurThER IMPROVEMENTS}

The LEGO-PoL design presented in this paper combines many state-of-the-art technologies together to achieve extreme 
TABLE III

Performance Comparison of the Vertical Stacked LEGO-Pol and Other 48 V to 1 V Point-of-Load Voltage Regulator Designs

\begin{tabular}{c|c|c|c|c|c|c|c|c}
\hline Year & Note & $\begin{array}{c}\text { Output } \\
\text { Current }\end{array}$ & $\begin{array}{c}\text { Power } \\
\text { Density }\end{array}$ & $\begin{array}{c}\text { Current Area } \\
\text { Density }\end{array}$ & $\begin{array}{c}\text { Peak } \\
\text { Efficiency }\end{array}$ & $\begin{array}{c}\text { Full Load } \\
\text { Efficiency }\end{array}$ & $\begin{array}{c}\text { Switching } \\
\text { Frequency }\end{array}$ & $\begin{array}{c}\text { Energy Storage per } \\
\text { Watt }\left(\frac{1}{2} L I^{2} / P\right)\end{array}$ \\
\hline $\begin{array}{c}\text { This } \\
\text { Work }\end{array}$ & $\begin{array}{c}\text { Liquid Cooled } \\
\text { Air Cooled }\end{array}$ & $\begin{array}{c}780 \mathrm{~A} \\
450 \mathrm{~A}\end{array}$ & $\begin{array}{c}1000 \mathrm{~W} / \mathrm{in}^{3} \\
577 \mathrm{~W} / \mathrm{in}^{3}\end{array}$ & $\begin{array}{c}1.017 \mathrm{~A} / \mathrm{mm}^{2} \\
0.587 \mathrm{~A} / \mathrm{mm}^{3}\end{array}$ & $\begin{array}{c}91.1 \% \\
91.1 \%\end{array}$ & $\begin{array}{c}79.2 \% \\
85.7 \%\end{array}$ & $1000 \mathrm{kHz}$ & $\begin{array}{c}400 \mathrm{~nJ} / \mathrm{W} \\
233 \mathrm{~nJ} / \mathrm{W}\end{array}$ \\
\hline \hline 2017 & TI [39] & $50 \mathrm{~A}$ & $129 \mathrm{~W} / \mathrm{in}^{3}$ & $0.079 \mathrm{~A} / \mathrm{mm}^{2}$ & $90.7 \%$ & $87.7 \%$ & $600 \mathrm{kHz}$ & $3125 \mathrm{~nJ} / \mathrm{W}$ \\
\hline 2019 & MP-MIH [40] & $40 \mathrm{~A}$ & $83 \mathrm{~W} / \mathrm{in}^{3}$ & $0.044 \mathrm{~A} / \mathrm{mm}^{2}$ & $92.1 \%$ & $80.4 \%$ & $300 \mathrm{kHz}$ & $14667 \mathrm{~nJ} / \mathrm{W}$ \\
\hline 2020 & QSD-Buck [41] & $40 \mathrm{~A}$ & $31 \mathrm{~W} / \mathrm{in}^{3}$ & $0.024 \mathrm{~A} / \mathrm{mm}^{2}$ & $94.5 \%$ & $91.1 \%$ & $125 \mathrm{kHz}$ & $10000 \mathrm{~nJ} / \mathrm{W}$ \\
\hline 2020 & MLB-PoL [42] & $65 \mathrm{~A}$ & $198 \mathrm{~W} / \mathrm{in}^{3}$ & $0.122 \mathrm{~A} / \mathrm{mm}^{2}$ & $93.1 \%$ & $86.8 \%$ & $250 \mathrm{kHz}$ & $9750 \mathrm{~nJ} / \mathrm{W}$ \\
\hline 2020 & Bel Power [43] & $70 \mathrm{~A}$ & $167 \mathrm{~W} / \mathrm{in}^{3}$ & $0.184 \mathrm{~A} / \mathrm{mm}^{2}$ & $91.6 \%$ & $90.5 \%$ & $242 \mathrm{kHz}$ & $\mathrm{N} / \mathrm{A}$ \\
\hline 2020 & Sigma [15] & $80 \mathrm{~A}$ & $420 \mathrm{~W} / \mathrm{in}^{3}$ & $0.127 \mathrm{~A} / \mathrm{mm}^{2}$ & $94.0 \%$ & $92.5 \%$ & $600 \mathrm{kHz}$ & $\mathrm{N} / \mathrm{A}$ \\
\hline 2020 & TSAB [44] & $90 \mathrm{~A}$ & $36 \mathrm{~W} / \mathrm{in}^{3}$ & $0.023 \mathrm{~A} / \mathrm{mm}^{2}$ & $91.5 \%$ & $85.0 \%$ & $500 \mathrm{kHz}$ & $3713 \mathrm{~nJ} / \mathrm{W}$ \\
\hline 2020 & Vicor [45], [46] & $214 \mathrm{~A}$ & $492 \mathrm{~W} / \mathrm{in}^{3}$ & $0.202 \mathrm{~A} / \mathrm{mm}^{2}$ & $90.9 \%$ & N/A & $1025 \mathrm{kHz}$ & $\mathrm{N} / \mathrm{A}$ \\
\hline 2021 & On-Chip [47] & $8 \mathrm{~A}$ & $198 \mathrm{~W} / \mathrm{in}^{3}$ & $0.031 \mathrm{~A} / \mathrm{mm}^{2}$ & $90.2 \%$ & $76 \%$ & $2500 \mathrm{kHz}$ & $353 \mathrm{~nJ} / \mathrm{W}$ \\
\hline 2021 & ADI [48] & $50 \mathrm{~A}$ & $89 \mathrm{~W} / \mathrm{in}^{3}$ & $0.064 \mathrm{~A} / \mathrm{mm}^{2}$ & $90.8 \%$ & $88.1 \%$ & $350 \mathrm{kHz}$ & $4125 \mathrm{~nJ} / \mathrm{W}$ \\
\hline 2021 & 24 V VIB [49] & $450 \mathrm{~A}$ & $325 \mathrm{~W} / \mathrm{in}^{3}$ & $0.219 \mathrm{~A} / \mathrm{mm}^{2}$ & $95.2 \%$ & $89.1 \%$ & $417 \mathrm{kHz}$ & $703 \mathrm{~nJ} / \mathrm{W}$ \\
\hline
\end{tabular}

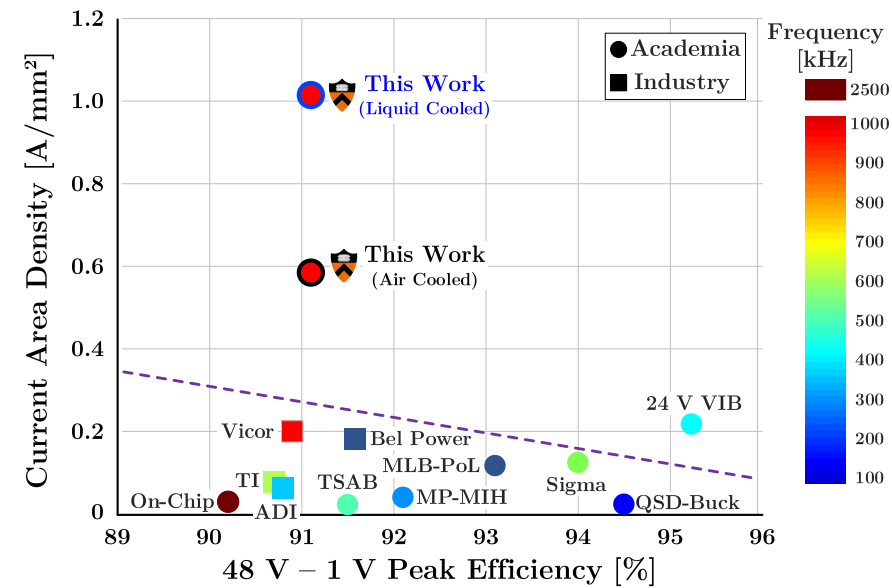

Fig. 29. Peak efficiency vs. current area density for the designs presented in Table III. Note these designs switch at different frequencies (color coded) and have different regulation capabilities. The LEGO-PoL converter switches at $1 \mathrm{MHz}$, among the highest in this comparison.

power density and efficiency. Some of its advantages come from the topology, architecture, and magnetics design, and other advantages come from the possibility of vertically packaging it together with the microprocessors to reduce the loss and parasitics in the interconnects, allowing more cores to be placed closer to each other with high speed communication. We envision that both the silicon power density and server power density will continue to increase in the near future. Both current area density $\left(\mathrm{A} / \mathrm{mm}^{2}\right)$ and power density $\left(\mathrm{W} / \mathrm{in}^{3}\right)$ of CPU voltage regulators are important design targets.

The presented prototype achieves its peak efficiency at around $20 \%$ of its thermal determined power (TDP). Depending on the applications, different microprocessors (e.g., CPUs, GPUs, XPUs) need performance optimized at different fractions of TDP, leading to different design tradeoffs. Different priorities among efficiency, density, and transient performance

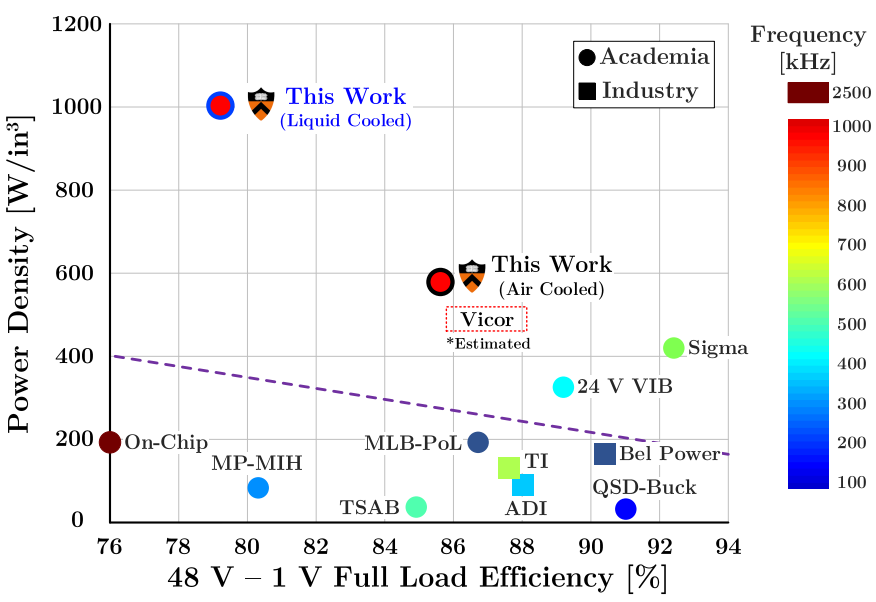

Fig. 30. Full load efficiency vs. power density for the designs presented in Table III. These designs switch at different frequencies and have different regulation capabilities. The LEGO-PoL converter switches at $1 \mathrm{MHz}$. The full load efficiency of the Vicor product is not available and is estimated.

also lead to different tradeoffs. Challenges and pathways to achieving over $4.5 \mathrm{~W} / \mathrm{mm}^{2}$ area density - matching that of a state-of-the-art of the silicon core - while maintaining a high efficiency across the entire operation range, include:

1) The DrMOS devices we used limit current area density, efficiency, and switching frequency. Better low-voltage power devices, whether based on $\mathrm{Si}$ or wide-bandgap semiconductors, are expected to be instrumental in overcoming all three of these limitations.

2) The height of the LEGO-PoL prototype is limited by the vertical coupled inductors and capacitors. Switching at a higher frequency, enabled by better switches; optimizing the magnetics design with a priority on reducing thickness; and more advanced capacitor technologies can further reduce the height and weight of the system.

3) The current throughput of the prototype is limited by the 
Weight Breakdown

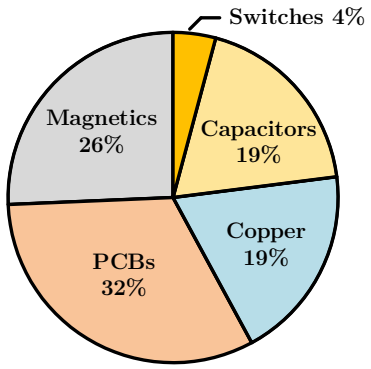

Volume Breakdown

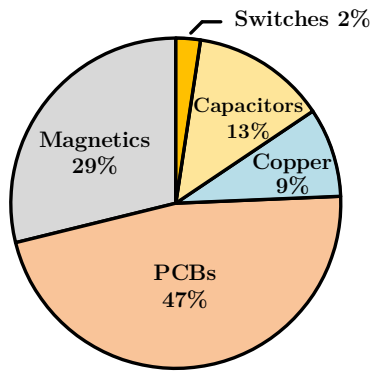

Fig. 31. Weight and volume breakdown of the LEGO-PoL prototype. The switches only contribute to $4 \%$ of the weight and $2 \%$ of the volume; capacitors and magnetics each occupy about one quarter, and the PCBs and copper boards contribute about one-half of the weight and volume.

thermal rating of the switches. Better cooling technology, and semiconductor devices that can work at a higher temperature (such as $\mathrm{GaN}$ devices), are promising techniques to improve the power density and improve the system efficiency at full load.

4) In the prototype, passive components (capacitors and magnetics) contribute an order of magnitude more volume and weight than the semiconductor devices. As shown in Fig. 31, semiconductor devices only contribute $4 \%$ of the system weight and 2\% of the system volume. Devices that can efficiently switch at a higher frequency can further reduce the passive component sizes.

5) Printed circuit boards (PCBs) and copper interconnects occupy a large percentage of the system weight and volume. Advanced packaging techniques are needed to further reduce the size and improve the current density.

\section{CONCLUSION}

This paper presents a vertical stacked $48 \mathrm{~V}$ to $1 \mathrm{~V}$ CPU voltage regulator with a linear-extendable group operated pointof-load architecture. By merging the operation of a switchedcapacitor stage and a multiphase buck stage, the advantages of both can be leveraged while decoupling the design challenges of high efficiency, high density, and high control bandwidth. A vertical stacked design enabled by a multiphase coupled inductor is presented to achieve a high power density and high current area density. The system is highly modular and scalable. The power converter modules are vertical stacked and have the potential to reach the current area density of silicon microprocessors by enabling vertical power delivery from the motherboard to the CPU. A $48 \mathrm{~V}$ to $1 \mathrm{~V}, 780 \mathrm{~A} \mathrm{CPU}$ voltage regulator is built and tested with air cooling and liquid cooling, achieving a $91.1 \%$ peak efficiency, a $1000 \mathrm{~W} / \mathrm{in}^{3}$ power density, and a $1.017 \mathrm{~A} / \mathrm{mm}^{2}$ current area density.

\section{APPENDIX I}

\section{Current Sharing and Voltage Balancing}

A large signal average analysis is performed to illustrate the principle of the automatic current sharing and voltage balancing mechanisms. In the three submodule system depicted in Fig. 3, assume the duty ratio of the buck converter, i.e., the duty ratio of high side switches, is $D, L_{x}$ is connected with a series resistance $R$, the large-signal average current of $L_{x}$ is $i_{x}$, the large-signal average voltage of $C_{y}$ is $v_{C_{y}}$, where $x \in\{1,2,3\}$ and $y \in\{2,4\}$, the large-signal average models are:

$$
\begin{gathered}
L_{1} \frac{d i_{L_{1}}}{d t}=\left\langle v_{L_{1}}\right\rangle=\frac{1}{2}\left(V_{i n}-v_{C_{2}}\right) D-v_{o}-i_{L_{1}} R, \\
L_{2} \frac{d i_{L_{2}}}{d t}=\left\langle v_{L_{2}}\right\rangle=\frac{1}{2}\left(v_{C_{2}}-v_{C_{4}}\right) D-v_{o}-i_{L_{2}} R, \\
L_{3} \frac{d i_{L_{3}}}{d t}=\left\langle v_{L_{3}}\right\rangle=\frac{1}{2} v_{C_{4}} D-v_{o}-i_{L_{3}} R . \\
C_{2} \frac{d v_{C_{2}}}{d t}=\left\langle i_{C_{2}}\right\rangle=\frac{1}{2}\left(D i_{L_{1}}-D i_{L_{2}}\right), \\
C_{4} \frac{d v_{C_{4}}}{d t}=\left\langle i_{C_{2}}\right\rangle=\frac{1}{2}\left(D i_{L_{2}}-D i_{L_{3}}\right) .
\end{gathered}
$$

Note $v_{C_{1}}, v_{C_{3}}$, and $v_{C_{5}}$ are canceled out in (4). They don't impact the large-signal dynamics. The charge balance requirement of capacitor $C_{2}$ and $C_{4}$ leads to the automatic current sharing mechanism among $L_{1}, L_{2}$, and $L_{3}$. Assuming that $L_{1}=L_{2}=L_{3}=L$ and $C_{2}=C_{4}=C$, the second-order differential equations for the current of the three submodule LEGO-PoL system can be obtained from (3):

$$
\begin{gathered}
\ddot{\mathbf{X}}+\frac{R}{L} \dot{\mathbf{X}}+\frac{D^{2}}{4 L C} \boldsymbol{M} \mathbf{X}=0, \\
\ddot{\mathbf{X}}=\left[\begin{array}{c}
\frac{d^{2} i_{L_{1}}}{d t^{2}} \\
\frac{d^{2} i_{L_{2}}}{d t^{2}} \\
\frac{d^{2} i_{L_{3}}}{d t^{2}}
\end{array}\right], \dot{\mathbf{X}}=\left[\begin{array}{c}
\frac{d i_{L_{1}}}{d t} \\
\frac{d i_{L_{2}}}{d t} \\
\frac{d i_{L_{3}}}{d t}
\end{array}\right], \mathbf{X}=\left[\begin{array}{l}
i_{L_{1}} \\
i_{L_{2}} \\
i_{L_{3}}
\end{array}\right], \\
\boldsymbol{M}=\left[\begin{array}{ccc}
1 & -1 & 0 \\
-1 & 2 & -1 \\
0 & -1 & 1
\end{array}\right], \\
\boldsymbol{Q}^{-1}=\frac{1}{6}\left[\begin{array}{ccc}
2 & 2 & 2 \\
-3 & 0 & 3 \\
1 & -2 & 1
\end{array}\right], \boldsymbol{\Lambda}=\left[\begin{array}{lll}
0 & 0 & 0 \\
0 & 1 & 0 \\
0 & 0 & 3
\end{array}\right] .
\end{gathered}
$$

Note $\boldsymbol{M}$ is a real symmetric matrix. $\boldsymbol{M}$ can be diagonalized as $\boldsymbol{M}=\boldsymbol{Q} \boldsymbol{\Lambda} \boldsymbol{Q}^{-1}$ where $\boldsymbol{Q}$ is a matrix composed of eigenvectors $\left(e_{1}, e_{2}\right.$, and $\left.e_{3}\right)$, and $\Lambda$ is a diagonal matrix composed of eigenvalues $\left(\lambda_{1}, \lambda_{2}\right.$, and $\left.\lambda_{3}\right)$ of $\boldsymbol{M}$. (5) can be rewritten as (6) by denoting $\boldsymbol{Y}=\boldsymbol{Q}^{-1} \mathbf{X}$ :

$$
\begin{gathered}
\ddot{\mathbf{Y}}+\frac{R}{L} \dot{\mathbf{Y}}+\frac{D^{2}}{4 L C} \boldsymbol{\Lambda} \mathbf{Y}=0 \\
\frac{d^{2} y_{1}}{d t^{2}}+\frac{R}{L} \frac{d y_{1}}{d t}+\frac{D^{2}}{4 L C}\left(\lambda_{1} y_{1}\right)=0 \\
\frac{d^{2} y_{2}}{d t^{2}}+\frac{R}{L} \frac{d y_{2}}{d t}+\frac{D^{2}}{4 L C}\left(\lambda_{2} y_{2}\right)=0 \\
\frac{d^{2} y_{3}}{d t^{2}}+\frac{R}{L} \frac{d y_{3}}{d t}+\frac{D^{2}}{4 L C}\left(\lambda_{3} y_{3}\right)=0
\end{gathered}
$$

Since $i_{L_{1}}-i_{L_{3}}$ is linearly proportional to $y_{2}$, the secondorder differential equation describing $i_{L_{1}}-i_{L_{3}}$ is:

$$
\frac{d^{2}\left(i_{L_{1}}-i_{L_{3}}\right)}{d t^{2}}+\frac{R}{L} \frac{d\left(i_{L_{1}}-i_{L_{3}}\right)}{d t}+\frac{D^{2}}{4 L C}\left(i_{L_{1}}-i_{L_{3}}\right)=0
$$



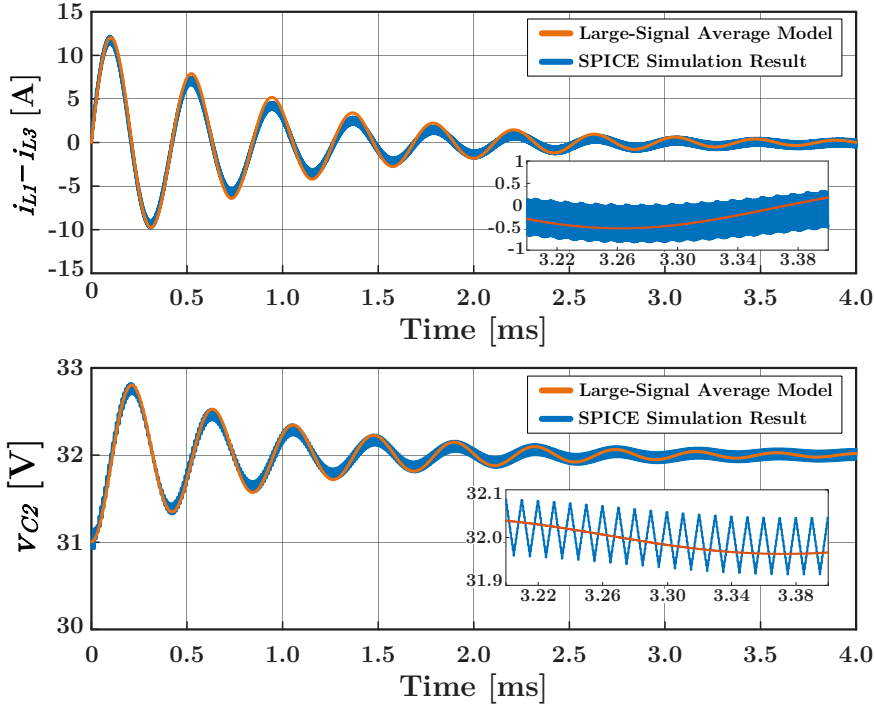

Fig. 32. Large-signal average model and SPICE simulated transient response of the automatic current sharing dynamics for the three submodule design in Fig. 3. The model was derived with $V_{i n}=48 \mathrm{~V}, D=0.2, L_{x}=1 \mu \mathrm{H}$, $C_{y}=45 \mu \mathrm{F}$, and $R=2 \mathrm{~m} \Omega$. The initial condition of this simulation: $i_{L_{1}}(0)=i_{L_{2}}(0)=i_{L_{3}}(0)=0 \mathrm{~A}, v_{C 2}(0)=31 \mathrm{~V}$, and $v_{C 4}(0)=15 \mathrm{~V}$. As described in (6), $v_{C 1}, v_{C 3}$, and $v_{C 5}$ have no impact on the transient dynamics. Their dc values are set by the switched capacitor mechanism due to the existence of the small $C_{\text {filter }}$.

This second-order differential equation describes the largesignal dynamics of the current difference between $i_{L_{1}}$ and $i_{L_{3}}$. The natural frequency $\omega_{n}$ of this second order oscillation system is $\frac{D}{2 \sqrt{L C}}$. The damping ratio $\zeta$ is $\frac{R}{D} \sqrt{\frac{C}{L}}$. The decay rate $\alpha$ is $\frac{R}{2 L}$, the quality factor $Q$ is $\frac{D}{2 R} \sqrt{\frac{L}{C}}$. The current difference will respond to perturbations like a second-order system, and gradually decay to zero in periodic steady state. As $i_{L_{1}}$ and $i_{L_{3}}$ converge, based on (5), since $y_{3}$ is proportional to $i_{L 1}-2 i_{L 2}+$ $i_{L 3}$, and $y_{3}$ damps to zero, all currents are equal in steady state. The current sharing mechanism of the LEGO-PoL converter is very similar to that of the series-capacitor buck converter [13]. As the current differences between inductors are zero, the average voltages of $C_{2}$ and $C_{4}, v_{C_{2}}$ and $v_{C_{4}}$, reach $\frac{2 V_{i n}}{3}$ and $\frac{V_{i n}}{3}$, respectively, because the average voltage across all switch nodes need to be equal. $v_{C_{1}}, v_{C_{3}}$, and $v_{C_{5}}$ are set by the switched capacitor mechanism due to the small filtering capacitor $C_{\text {filter }}$. This guarantees automatic voltage balancing of the LEGO-PoL architecture.

Figure 32 compares the large-signal average model against SPICE simulation results. In periodic steady state, the large signal current $i_{L_{1}}=i_{L_{3}}$, and $\frac{d i_{L_{1}}}{d t}=\frac{d i_{L_{3}}}{d t}=0$. This mechanism holds the large-signal average of $v_{C_{2}}$ at $\frac{2}{3} V_{i n}$ and the transient dynamics of the capacitor voltage follows a similar second-order transient dynamic (similar damping ratio and $Q$ ) as $i_{L_{1}}-i_{L_{3}}$ and gradually damps to $\frac{2}{3} V_{i n}$ following the same oscillation. $V_{C_{2}}$ will be automatically maintained at $\frac{2}{3} V_{i n}$ in this example implementation.

This analysis can be extended and generalized for a LEGOPoL converter with $N$ submodules. Assuming that $L_{1}=L_{2}=$ $\ldots=L_{N}=L$ with series resistance $R_{1}=R_{2}=\ldots=R_{N}=$ $R, C_{2}=C_{4}=\ldots=C_{2(N-1)}=C$, and the duty ratio of all buck units high side switches is $D$, the large-signal average model of the system is:

$$
\begin{gathered}
\ddot{\mathbf{X}}+\frac{R}{L} \dot{\mathbf{X}}+\frac{D^{2}}{4 L C} \boldsymbol{M} \mathbf{X}=0 \\
\ddot{\mathbf{X}}=\left[\begin{array}{c}
\frac{d^{2} i_{L_{1}}}{d t^{2}} \\
\frac{d^{2} i_{L_{2}}}{d t^{2}} \\
\vdots \\
\frac{d^{2} i_{L_{N}}}{d t^{2}}
\end{array}\right], \dot{\mathbf{X}}=\left[\begin{array}{c}
\frac{d i_{L_{1}}}{d t} \\
\frac{d i_{L_{2}}}{d t} \\
\vdots \\
\frac{d i_{L_{N}}}{d t}
\end{array}\right], \mathbf{X}=\left[\begin{array}{c}
i_{L_{1}} \\
i_{L_{2}} \\
\vdots \\
i_{L_{N}}
\end{array}\right], \\
\boldsymbol{M}=\left[\begin{array}{cccccc}
1 & -1 & 0 & 0 & \ldots & 0 \\
-1 & 2 & -1 & 0 & \cdots & 0 \\
0 & -1 & 2 & -1 & \cdots & 0 \\
\vdots & \vdots & \vdots & \ddots & \ldots & \vdots \\
0 & 0 & \cdots & -1 & 2 & -1 \\
0 & 0 & \cdots & 0 & -1 & 1
\end{array}\right] \\
\mathbf{X}^{T} \cdot \boldsymbol{M} \cdot \mathbf{X}=\sum_{k=1}^{N-1}\left(x_{k+1}-x_{k}\right)^{2} \geq 0
\end{gathered}
$$

$\boldsymbol{M}$ is a $N \times N$ real symmetric matrix, so it can be diagonalized as $\boldsymbol{M}=\boldsymbol{Q} \boldsymbol{\Lambda} \boldsymbol{Q}^{-1}$, where $\boldsymbol{Q}=\left[e_{1}, e_{2}, \ldots, e_{N}\right]$ and $\boldsymbol{\Lambda}$ is the diagonal matrix consisting of eigenvalues $\left(\lambda_{1}, \lambda_{2}, \ldots, \lambda_{N}\right)$. For any non-zero $\mathbf{x}=\left[x_{1}, x_{2}, \ldots, x_{N}\right]^{T}, \boldsymbol{M}$ satisfies (9), so $\boldsymbol{M}$ is positive semidefinite, i.e. $\lambda_{k} \geq 0$, where $k \in\{1,2, \ldots, N\}$. The rank of $\boldsymbol{M}$ is $N-1$, so there exists one and only one zero eigenvalue. Assuming $\lambda_{1}=0$, the corresponding eigenvector $\boldsymbol{e}_{\mathbf{1}}$ is $[1,1, \ldots, 1]^{T}$. Denoting $\boldsymbol{Y}=\boldsymbol{Q}^{-1} \mathbf{X}$, then (8) can be rewritten as (10) with explicit solutions:

$$
\left\{\begin{array}{l}
\frac{d^{2} y_{1}}{d t^{2}}+\frac{R}{L} \frac{d y_{1}}{d t}=0, \quad k=1 \\
\frac{d^{2} y_{k}}{d t^{2}}+\frac{R}{L} \frac{d y_{k}}{d t}+\left(\frac{D^{2} \lambda_{k}}{4 L C}\right) y_{k}=0, \quad k=\{2,3, \ldots, N\}
\end{array}\right.
$$

The general solutions for (10) are:

$$
\left\{\begin{array}{l}
y_{1}(t)=K_{11} e^{(-2 \alpha t)}+K_{12}, \quad k=1 \\
y_{k(k \geq 2)}(t)=K_{k 1} e^{\left(-\alpha+\beta_{k}\right) t}+K_{k 2} e^{\left(-\alpha-\beta_{k}\right) t},
\end{array}\right.
$$

where $K_{1}, K_{2}, K_{k 1}$ and $K_{k 2}$ are constant coefficients, $\alpha=$ $\frac{R}{2 L}, \beta_{k}=\frac{1}{2} \sqrt{\left(\frac{R}{L}\right)^{2}-\frac{D^{2} \lambda_{k}}{L C}}$. There are three cases for the solution of $y_{k(k \geq 2)}(t)$ : two different real roots, repeated roots, and complex roots. In all three cases, since $\alpha$ is positive, $y_{1}(t)$ damps to $K_{12}$ and $y_{k(k \geq 2)}(t)$ damps to zero as $t \rightarrow \infty$. Therefore, in periodic steady state, the large signal inductor currents of the LEGO-PoL architecture with $N$ submodules and total system output current $I_{O}$ will settle to the same constant value $K_{12}=\frac{I_{O}}{N}$ :

$$
\left[\begin{array}{c}
i_{L 1} \\
i_{L 2} \\
\vdots \\
i_{L N}
\end{array}\right]=\boldsymbol{Q Y}=\left[\boldsymbol{e}_{\mathbf{1}}, \boldsymbol{e}_{\mathbf{2}}, \ldots, \boldsymbol{e}_{\boldsymbol{N}}\right]\left[\begin{array}{c}
K_{12} \\
0 \\
\vdots \\
0
\end{array}\right]=\left[\begin{array}{c}
K_{12} \\
K_{12} \\
\vdots \\
K_{12}
\end{array}\right] .
$$

Similarly, the average capacitor voltages $V_{C_{2}}$, $V_{C_{4}}, \ldots, V_{C_{2(N-1)}}$ damp to a balanced voltage: 


$$
\left[\begin{array}{c}
V_{C_{2}} \\
V_{C_{4}} \\
\vdots \\
V_{C_{2(N-1)}}
\end{array}\right]=\frac{V_{i n}}{N}\left[\begin{array}{c}
N-1 \\
N-2 \\
\vdots \\
1
\end{array}\right] .
$$

The voltages of other capacitors are then balanced by the switched capacitor mechanism due to the existence of $C_{\text {filter }}$. The charge balancing mechanism of the series capacitors guarantees automatic current sharing and automatic voltage balancing for the LEGO-PoL architecture with $N$ submodules.

\section{REFERENCES}

[1] J. Baek, P. Wang, S. Jiang, and M. Chen, "LEGO-PoL: A 93.1\% 54V$1.5 \mathrm{~V} 300 \mathrm{~A}$ Merged-Two-Stage Hybrid Converter with a Linear Extendable Group Operated Point-of-Load (LEGO-PoL) Architecture," IEEE Workshop on Control and Modeling of Power Electronics (COMPEL), Toronto, Canada, 2019.

[2] J. Baek, P. Wang, Y. Elasser, Y. Chen, S. Jiang, and M. Chen, "LEGOPoL: A 48V-1.5V 300A Merged-Two-Stage Hybrid Converter for UltraHigh-Current Microprocessors," IEEE Applied Power Electronics Conference and Exposition (APEC), New Orleans, LA, USA, 2020.

[3] Y. Elasser, J. Baek, and M. Chen, "A Merged-Two-Stage LEGO-PoL Converter with Coupled Inductors for Vertical Power Delivery," IEEE Energy Conversion Congress and Exposition, Detroit, MI, USA, 2020.

[4] J. Baek, Y. Elasser, and M. Chen, "3D LEGO-PoL: A 93.3\% Efficient 48V-1.5V 450A Merged-Two-Stage Hybrid Switched-Capacitor Converter with 3D Vertical Coupled Inductors," IEEE Applied Power Electronics Conference and Exposition, Phoenix, AZ, USA, 2021.

[5] R. H. Dennard, F. H. Gaensslen, H. N. Yu, V. L. Rideout, E. Bassous, A LeBlanc, "Design of Ion-Implanted MOSFET's with Very Small Physical Dimensions," IEEE Journal of Solid-State Circuits, vol. 9, no. 5, pp. 256-268, October 1974.

[6] S. Borkar and A. A. Chien, "The Future of Microprocessors," Соттиnications of the ACM., vol. 54, no. 5, pp. 67-77, May 2011.

[7] "Preventing Chips From Burning Up During Test," Semiconductor Engineering, 2021 [online]. https://semiengineering.com/preventing-chipsfrom-burning-up-during-test

[8] "GPU Die Size \& Process Technology," PC Watch [online]. Available: https://pc.watch.impress.co.jp/img/pcw/docs/752/331/html/6.jpg.html

[9] A. Shehabi et al., "United States Data Center Energy Usage Report," Lawrence Berkeley National Laboratory, Berkeley, CA, Tech.Rep. LBNL-1005775, June, 2016. [online]. Available: https://etapublications.lbl.gov/sites/default/files/lbnl-1005775_v2.pdf

[10] E. Strubell, A. Ganesh, and A. McCallum, "Energy and Policy Considerations for Modern Deep Learning Research," Proceedings of the AAAI Conference on Artificial Intelligence, vol. 34, no. 09, April 2020.

[11] X. Li and S. Jiang, "Google 48V Rack Adaptation and Onboard Power Technology Update," Open Compute Project (OCP) Global Summit, San Jose, CA, USA, 2019.

[12] K. Nishijima, K. Harada, T. Nakano, T. Nabeshima, and T. Sato, "Analysis of Double Step-Down Two-Phase Buck Converter for VRM," International Telecommunications Conference (INTELEC), Berlin, Germany, 2005.

[13] P. S. Shenoy et al., "A $5 \mathrm{MHz}, 12 \mathrm{~V}, 10 \mathrm{~A}$, Monolithically Integrated Two-Phase Series Capacitor Buck Converter," IEEE Applied Power Electronics Conference and Exposition (APEC), Long Beach, CA, USA, 2016.

[14] T. Xie, R. Das, G.-S. Seo, D. Maksimović, and H.-P. Le, "Multiphase Control for Robust and Complete Soft-charging Operation of Dual Inductor Hybrid Converter," IEEE Applied Power Electronics Conference and Exposition (APEC), Anaheim, CA, USA, 2019.

[15] M. H. Ahmed, C. Fei, F. C. Lee, and Q. Li, "Single-Stage HighEfficiency 48/1 V Sigma Converter With Integrated Magnetics," IEEE Trans. on Ind. Electronics, vol. 67, no. 1, pp. 192-202, January 2020.

[16] G.-S. Seo, R. Das, and H.-P. Le, "Dual Inductor Hybrid Converter for Point-of-Load Voltage Regulator Modules," IEEE Transactions on Industry Applications, vol. 56, no. 1, pp. 367-377, Jan./Feb. 2020.

[17] C. Fei, M. H. Ahmed, F. C. Lee, and Q. Li, "Two-Stage 48 V-12 V/6 V-1.8 V Voltage Regulator Module With Dynamic Bus Voltage Control for Light-Load Efficiency Improvement," IEEE Transactions on Power Electronics, vol. 32, no. 7, pp. 5628-5636, July 2017.
[18] M. H. Ahmed, C. Fei, F. C. Lee, and Q. Li, "48-V Voltage Regulator Module With PCB Winding Matrix Transformer for Future Data Centers," IEEE Trans. on Ind. Electron., vol.64, no.12, pp.9302-9310, Dec. 2017.

[19] Y. Cai, M. H. Ahmed, Q. Li, and F. C. Lee, "Optimal Design of Megahertz LLC Converter for 48-V Bus Converter Application," IEEE Journal of Emerging and Selected Topics in Power Electronics, vol. 8, no. 1, pp. 495-505, March 2020.

[20] Y. Li, X. Lyu, D. Cao, S. Jiang, and C. Nan, "A 98.55\% Efficiency Switched-Tank Converter for Data Center Application," IEEE Trans. on Industry Applications, vol. 54, no. 6, pp. 6205-6222, Nov./Dec. 2018.

[21] S. Jiang, S. Saggini, C. Nan, X. Li, C. Chung, and M. Yazdani, "Switched Tank Converters," IEEE Transactions on Power Electronics, vol. 34, no. 6, pp. 5048-5062, June 2019.

[22] P. H. McLaughlin, P. A. Kyaw, M. H. Kiani, C. R. Sullivan, and J. T. Stauth, "Two-Phase Interleaved Resonant Switched-Capacitor DC-DC Converter with Coupled Inductors and Custom LC Resonator," IEEE Applied Power Electronics Conference and Exposition (APEC), Anaheim, CA, USA, 2019.

[23] Z. Ye, Y. Lei, and R. C. N. Pilawa-Podgurski, "The Cascaded Resonant Converter: A Hybrid Switched-Capacitor Topology With High Power Density and Efficiency," IEEE Transactions on Power Electronics, vol. 35, no. 5, pp. 4946-4958, May 2020.

[24] J. Zhu and D. Maksimović, "Transformerless Stacked Active Bridge Converters: Analysis, Properties, and Synthesis," IEEE Transactions on Power Electronics, vol. 36, no. 7, pp. 7914-7926, July 2021.

[25] P. L. Wong, P. Xu, B. Yang, and F. C. Lee, "Performance Improvements of Interleaving VRMs with Coupling Inductors," IEEE Transactions on Power Electronics, vol. 16, no. 4, pp. 499-507, July 2001.

[26] J. Li, C. R. Sullivan, and A. Schultz, "Coupled Inductor Design Optimization for Fast-Response Low-Voltage DC-DC Converters," IEEE Applied Power Electronics Conference and Exposition (APEC), Dallas, TX, USA, 2002.

[27] J. Li, A. Stratakos, A. Schultz, and C. R. Sullivan, "Using Coupled Inductors to Enhance Transient Performance of Multi-Phase Buck Converters," IEEE Applied Power Electronics Conference and Exposition (APEC), Anaheim, CA, USA, 2004.

[28] M. Xu, J. Zhou, K. Yao, and F. C. Lee, "Small Signal Modeling of a High Bandwidth Voltage Regulator Using Coupled Inductors," IEEE Trans. on Power Electronics, vol. 22, no. 2, pp. 399-406, March 2007.

[29] M. Chen and C. R. Sullivan, "Unified Models for Coupled Inductors Applied to Multiphase PWM Converters," IEEE Transactions on Power Electronics, accepted.

[30] C. R. Sullivan and M. Chen, "Coupled Inductors for Fast-Response High-Density Power Delivery: Discrete and Integrated," IEEE Custom Integrated Circuits Conference (CICC), Austin, TX, USA, 2021.

[31] D. Zhou, Y. Elasser, J. Baek, C. R. Sullivan, and M. Chen, "Inductance Dual Model and Control of Multiphase Coupled Inductor Buck Converter," IEEE Workshop on Control and Modeling of Power Electronics (COMPEL), Aalborg, Denmark, 2020.

[32] Y. Elasser, J. Baek, C. R. Sullivan, and M. Chen, "Modeling and Design of Vertical Multiphase Coupled Inductors with Inductance Dual Model," IEEE Applied Power Electronics Conference and Exposition (APEC), Phoenix, AZ, USA, 2021.

[33] R. C. N. Pilawa-Podgurski, D. M. Giuliano, and D. J. Perreault, "Merged Two-Stage Power Converter Architecture with SoftCharging Switched-Capacitor Energy Transfer," IEEE Power Electronics Specialists Conference, Rhodes, Greece, 2008.

[34] D. M. Giuliano, M. E. D'Asaro, J. Zwart, and D. J. Perreault, "Miniaturized Low-Voltage Power Converters With Fast Dynamic Response," IEEE Journal of Emerging and Selected Topics in Power Electronics, vol. 2, no. 3, pp. 395-405, September 2014.

[35] J. Sun, J. Q. Lu, D. Giuliano, T. P. Chow, and R. J. Gutmann, "3D Power Delivery for Microprocessors and High-Performance ASICs," IEEE Applied Power Electronics Conference and Exposition (APEC), Anaheim, CA, USA, 2007.

[36] C. Buttay, C. Martin, F. Morel, R. Caillaud, J. Le Leslé, R. Mrad, N. Degrenne, and S. Mollov, "Application of the PCB-Embedding Technology in Power Electronics - State of the Art and Proposed Development," International Symposium on 3D Power Electronics Integration and Manufacturing (3D-PEIM), College Park, MD, USA, 2018.

[37] W. J. Lambert, M. J. Hill, K. Radhakrishnan, L. Wojewoda, and A. E. Augustine, "Package Inductors for Intel Fully Integrated Voltage Regulators," IEEE Transactions on Components, Packaging and Manufacturing Technology, vol. 6, no. 1, pp. 3-11, January 2016.

[38] N. Sturcken et al., "A 2.5D Integrated Voltage Regulator Using CoupledMagnetic-Core Inductors on Silicon Interposer," IEEE Journal of SolidState Circuits, vol. 48, no. 1, pp. 244-254, January 2013. 
[39] "Using the LMG5200POLEVM-10 48V to Point of Load EVM," Texas Instruments, 2017 [online]. Available: https://www.ti.com/lit/ug/snvu520b /snvu520b.pdf

[40] R. Das, G.-S. Seo, D. Maksimović, and H.-P. Le, "An 80-W 94.6\%Efficient Multi-Phase Multi-Inductor Hybrid Converter," IEEE Applied Power Electronics Conference and Exposition, Anaheim, CA, USA, 2019.

[41] M. Halamicek, T. McRae, and A. Prodić, "Cross-Coupled SeriesCapacitor Quadruple Step-Down Buck Converter," IEEE Applied Power Electronics Conference and Exposition, New Orleans, LA, USA, 2020.

[42] Z. Ye, R. A. Abramson, Y.-L. Syu, and R. C. N. Pilawa-Podgurski, "MLB-PoL: A High Performance Hybrid Converter for Direct $48 \mathrm{~V}$ to Point-of-Load Applications," IEEE Workshop on Control and Modeling of Power Electronics (COMPEL), Aalborg, Denmark, 2020.

[43] "Main \& Satellite Power Stamp 48V-to-PoL Isolated DC-DC Converters," Bel, 2020 [online]. Available: https://www.belfuse.com/resources/ datasheets/powersolutions/ds-bps-48-v-to-pol-power-stamp.pdf

[44] J. Zhu and D. Maksimović, "48 V-to-1 V Transformerless Stacked Active Bridge Converters with Merged Regulation Stage," IEEE Workshop on Control and Modeling for Power Electronics (COMPEL), Aalborg, Denmark, 2020.

[45] "PRM Regulator PRM48BH480T250A00," Vicor, 2020 [online]. Available: http://www.vicorpower.com/documents/datasheets/PRM48BH480T 250A00_ds.pdf

[46] "VTM Current Multiplier VTM48MP010x107AA1," Vicor, 2017 [online]. Available: http://www.vicorpower.com/documents/datasheets/VTM 48M_010_107AA1.pdf

[47] X. Yang et al., "An 8A 998A/inch 3 90.2\% Peak Efficiency 48V-to-1V DC-DC Converter Adopting On-Chip Switch and GaN Hybrid Power Converter,' IEEE International Solid-State Circuits Conference (ISSCC), San Francisco, CA, USA, 2021.

[48] "LTM4664 54VIN Dual 25A, Single 50A $\mu$ Module Regulator with Digital Power System Management," Analog Devices, 2021 [online], Available: https://www.analog.com/media/en/technicaldocumentation/data-sheets/ltm4664.pdf

[49] Y. Chen, H. Cheng, G. Szczeszynski, S. Allen, D. M. Giuliano, and M. Chen, "Virtual Intermediate Bus CPU Voltage Regulator," IEEE Trans. on Power Electronics, Under Review. 